https://doi.org/10.7203/Normas.3.4676

\title{
NORMA Y VARIACIÓN LINGÜÍSTICA: PARALELISMOS Y DIVERGENCIAS ENTRE EL ESPAÑOL Y EL CATALÁN
}

\author{
LINGUISTIC VARIATION AND NORM: PARALLELISMS AND DIVERGENCES \\ BETWEEN SPANISH AND CATALAN \\ Joan-Rafael RAMOS \\ Universitat de València
}

\section{RESUMEN:}

Este artículo analiza la presencia de la variación lingüística de carácter dialectal en la norma académica o modelo de lengua estándar del español y del catalán. Esta variación se manifiesta a través de la aceptación de alternativas normativas, también conocida como polimorfismo. El estudio se centra en la lengua escrita, concretamente en el nivel ortográfico, en el morfológico y en el sintáctico, y analiza los contenidos de las principales obras académicas de estas dos lenguas. El hecho de tratarse de lenguas con una situación sociolingüística diferente tiene consecuencias en la manera de concebir el posible polimorfismo y también en la forma de aplicarlo, ya que entra en conflicto la defensa de un único modelo estándar frente a la permisividad de más de un modelo estándar por razones de identidad geográfica.

PALABRAS CLAVE: norma, variación lingüística, español, catalán, gramática, lengua estándar.

\section{ABSTRACT:}

This article analyses the presence of dialectal linguistic variation in the academic norm or model of standard Spanish and Catalan language. This variation becomes manifest through the acceptance of normative alternatives, a phenomenon also known as polymorphism. The study focuses on the written language, with special emphasis on the orthographic, morphological and syntactic levels, and analyses the contents of the main academic works in the two languages. The fact that they are languages with different sociolinguistic situations affects the way the possible polymorphism is conceived, as well as the way it is applied, since the defence of a single standard model clashes with the permissiveness of allowing more than one standard model for reasons that have to do with geographical identity.

KEY WORDS: norm, linguistic variation, Spanish, Catalan, grammar, standard language.

NORMAS. REVISTA DE ESTUDIOS LINGÜÍSTICOS HISPÁNICOS, NÚMERO 3 (AÑO 2013):

http://www.uv.es/normas

(ISSN 2174-7245) 


\section{INTRODUCCIÓN}

La no identificación con la norma o, si se quiere, la reivindicación de soluciones dialectales diferentes a la norma establecida, no es un hecho extraño en comunidades lingüísticas donde la lengua ocupa territorios de diferente nacionalidad o se distribuye en zonas regionales con un fuerte sentimiento autónomo. Al lado de esta reivindicación, hay quien pone el grito en el cielo en defensa de la unidad de la lengua y denuncia que aceptar soluciones alternativas a la norma establecida puede suponer la fragmentación de la lengua. Diversos autores han utilizado la palabra «tensión» para visualizar este conflicto entre norma y variación, y ha sido tema de debate tanto en el ámbito español como en el catalán ${ }^{1}$.

El presente artículo pretende profundizar en este debate y mostrar cómo la situación sociolingüística en que se enmarca una lengua puede hacer variar el grado de aceptación de la variación lingüística en la norma académica.

Por razones de espacio, no nos ocuparemos de este conflicto en la lengua oral, sino que nos centraremos en la lengua escrita. Tampoco trataremos aspectos relacionados con el léxico, sino solamente gramaticales. Nuestra intención es estudiar la presencia de la variación dialectal en la norma ortográfica, morfológica y sintáctica. Para ello, analizaremos y contrastaremos las principales obras normativas del español y del catalán, y estableceremos las diferencias de posicionamiento a la hora de aceptar alternativas normativas o de descartarlas.

\section{SOBRE EL CONCEPTO DE NORMA Y VARIACIÓN LINGÜÍSTICA}

Cualquier lengua natural, como ente vivo, no se manifiesta como un sistema homogéneo y sin cambios, sino que está sujeta a una variación que de alguna manera determina sus características y la hace diferente a las otras. Esto afecta tanto a las lenguas llamadas de cultura como a aquellas lenguas que, por razones históricas, no disponen de una tradición escrita.

La muestra más evidente de esta variación lingüística dentro de una misma lengua se observa en las diferencias que hay entre sus usuarios, pero también en los usos que hacen de la lengua estos usuarios. En este sentido, de acuerdo con Gregory y Carroll (1978), podemos distinguir respectivamente entre variedades dialectales y registros (cf. Marí, 1987; Bibiloni, 2004). Las variedades dialectales poden de manifiesto las formas diferentes de hablar por el hecho de pertenecer a una zona geográfica determinada. Esto determina que haya grupos de hablantes que se identifiquen con un dialecto concreto y que perciban su forma de hablar como distinta a la de grupos de hablantes de otras áreas de la misma lengua. Por otro lado, los registros están relacionados con la utilización que hacen los usuarios de esa variedad dialectal según la situación comunicativa, lo cual significa que pueden entrar en juego otros factores que condicionan, interactúan y hacen

\footnotetext{
${ }^{1}$ Entre otras muchas referencias, a modo de ilustración, podemos citar: Narbona (2001), Rivarola (2001), Demonte (2004), Moreno Cabrera (2011: 265), Bibiloni (2004: 115-119), Solà (2004), Ginebra y Solà (2007, 103-114).
}

NORMAS. REVISTA DE ESTUDIOS LINGÜÍSTICOS HISPÁNICOS, NÚMERO 3 (AÑO 2013):

http://www.uv.es/normas

(ISSN 2174-7245) 
variar la lengua del usuario. Estos factores están relacionados con el tema del cual se habla (campo temático), con las características formales del discurso (modo o canal de comunicación: oral, escrito, audiovisual, etc.), con el propósito de la comunicación (tenor funcional) y con el nivel de formalidad (tenor interpersonal).

Si la variación es consustancial a las lenguas, la pregunta que nos tenemos que hacer es qué es lo que hace posible que un hablante considere que pertenece a una determinada comunidad lingüística. La primera respuesta debería ser la intercomprensión fluida con el resto de los hablantes de la comunidad. Pero esto puede resultar problemático, ya que hay comunidades lingüísticas reconocidas internacionalmente que presentan dificultades de comprensión oral, caso del chino o del mismo italiano. La segunda respuesta nos lleva directamente al uso escrito de una lengua. Tal y como ha advertido Nadal (2006), a través de la escritura se consigue neutralizar o, lo que es lo mismo, ocultar la variación de la lengua oral. Además, el modelo escrito va unido generalmente a un proyecto nacional que conlleva un interés por homogeneizar la lengua con el fin de potenciar la unidad lingüística y preservarla de las otras lenguas vecinas. Este proyecto se suele vehicular por medio de instituciones académicas, que proponen un modelo de corrección lingüística que hay que seguir, la norma.

En estas actuaciones históricas, propias de una planificación lingüística, el concepto de norma no se identifica con el uso «normal»o habitual de la lengua, sino que va ligado a un modelo de prestigio: el modelo utilizado por las clases sociales o grupos de poder dominantes (Nicolás, 2006). Por tanto, es la élite la que decide, a veces de manera bastante arbitraria, qué es correcto o incorrecto. En este sentido, un modelo que no tiene por qué ser el más extendido se convierte en normal gracias a la política linguiística de un estado. Y lo que no era normal o habitual acaba imponiéndose y defendiéndose como normal. Un fragmento en la primera página de la presentación del Diccionario Panhispánico de Dudas (DPD, 2005) nos permite ilustrar esta maniobra restrictiva que supone el concepto de norma:

La norma, que el Diccionario académico define como «conjunto de criterios lingüísticos que regulan el uso considerado recto», no es algo decidido y arbitrariamente impuesto desde arriba: lo que las Academias hacen es registrar el consenso de la comunidad de los hispanohablantes y declarar norma, en el sentido de regla, lo que estos han convertido en hábito de corrección, siguiendo los modelos de la escritura o del habla considerados cultos.

Este interés por que la norma, ligada a la corrección lingüística, sea una realidad social nos lleva al concepto de variedad estándar, de manera que a menudo los conceptos de norma y estándar se acaban confundiendo. La definición del concepto de estándar no es sencilla (cf. Solà, 2000; Bibiloni, 2004: 75-79; Demonte, 2004: 17). Asociado en un principio a un tipo de comunicación formal y pública, y como modelo de referencia de comunicación interdialectal (también denominado modelo neutro, común o general), no resulta extraña su identificación como un registro de lengua intermedio en oposición al lenguaje coloquial y al lenguaje más elaborado o especializado. Pero su caracterización es mucho más compleja, ya que puede haber usuarios en los que, en la lengua oral, las diferencias entre el registro formal y el 
coloquial son poco perceptibles. Por otro lado, sobre todo en los medios audiovisuales, basados en un guion escrito (series televisivas, películas), el denominado modelo estándar se amplía para poder cubrir situaciones comunicativas diferentes, a menudo de carácter informal, con lo cual la correspondencia entre norma, como lo correcto, y estándar se relativiza, y da paso al concepto de adecuación (Narbona, 2001). No se trata, pues, de establecer qué es correcto y qué no lo es, sino de determinar qué es adecuado y qué no lo es según la situación comunicativa. En este sentido, una forma gramatical, aunque no sea normativa, puede considerarse adecuada en una situación comunicativa poco formal (o incluso oral), pero inadecuada en un registro formal. El paso del tiempo también puede hacer que esa misma forma acabe siendo aceptada por la norma, tal y como pone de manifiesto la actualización de las normas gramaticales por parte de las instituciones académicas.

Conceptos, pues, como norma, correcto, estándar y adecuado se entrecruzan como consecuencia del uso que hace el hablante de la lengua. Pero la pregunta que nos deberíamos hacer ahora es: ¿por qué el hablante se aparta de la norma, del estándar, o si se quiere, del uso correcto y adecuado? La respuesta es muy sencilla: porque su variedad dialectal también es posible que se aparte, poco o mucho, del modelo aceptado como normativo y, por tanto, como estándar. Esto significa que entra en conflicto su variedad dialectal, como hablante de una lengua, y el modelo que académicamente se ha considerado normativo. En general, cuanto más culturizada y cohesionada sea una comunidad lingüística, menos conflictos se suelen dar. Pero también es posible que el conflicto surja por una falta de identificación con la norma, con el estándar. En este sentido, el español y el catalán han afrontado el tema de manera diferente.

\section{LAS INSTITUCIONES NORMATIVAS Y LA VARIACIÓN LINGÜÍSTICA}

Como hemos advertido en el apartado anterior, la codificación gramatical de una lengua se suele llevar a cabo a través de instituciones académicas que tienen el aval político. Pero razones históricas han hecho que los caminos emprendidos por el español y por el catalán para la codificación gramatical hayan sido distintos.

\subsection{El caso del español}

La creación de la Real Academia Española de la Lengua (RAE) en el siglo XVIII marca el devenir de la codificación gramatical del español (Lliteras, 2006; Ricós, 2011). La publicación de sus diccionarios, tratados de ortografía y gramática, gracias a su alianza con el estado, va calando en el sistema educativo español y en la homogeneización de la producción editorial.

En un primer momento, el criterio de autoridad para fijar la normativa son los autores españoles del periodo literario de los Siglos de Oro. Pero en el siglo XIX ya se producen las primeras muestras de desacuerdo con esta codificación. El proceso de independencia de las colonias americanas aumenta el sentimiento nacional de los nuevos países y se producen algunos intentos de apartarse de la normativa emanada 
desde España. La misma RAE consigue frenar esta tendencia con la conocida estrategia de creación, a modo de sucursal, de una academia de la lengua para cada uno de los países americanos. Esto permite neutralizar los intentos rupturistas y seguir controlando el modelo normativo, consolidado sobre la base del castellano peninsular central y septentrional.

Aunque la diversidad dialectal es un hecho bien constatable ${ }^{2}$, como apunta Lliteras (2006), no será hasta la publicación del Esbozo en 1973 cuando se introducen importantes novedades en cuanto al criterio de autoridad normativa. A pesar de que continúan justificándose soluciones con testimonios clásicos, los cambios sociales obligan a tener en cuenta la lengua hablada, la literatura contemporánea, y sobre todo

por primera vez en la historia de la gramática académica, autores hispanoamericanos y publicaciones periódicas del Nuevo Continente entran a formar parte de este archivo sobre el que se construye la norma, desde entonces panhispánica, del idioma (Lliteras, 2006: 69).

El precedente ideológico había sido la organización del Primer Congreso de las Academias de la Lengua Española (1951), la creación de la Asociación de Academias de la Lengua Española (1952) y la celebración periódica de congresos internacionales de esta asociación, con el objetivo básico de velar por la unidad y la integridad del idioma. El próximo paso para fijar la denominada norma panhispánica son las publicaciones recientes del Diccionario Panhispánico de Dudas (DPD) (2005), la Nueva Gramática de la Lengua Española (NGLE) $(2009,2011)$ y la Ortografía de la Lengua Española (OLE) (2010), redactadas por la RAE y la Asociación de Academias de la Lengua Española, y la información gramatical que contienen las entradas de la actualización del Diccionario de la RAE (2001) ${ }^{3}$. El prólogo de la NGLE vuelve a insistir en este aspecto:

Son dos los criterios fundamentales que han guiado el trabajo de las Academias en lo relativo a este punto. El primero y más importante es la asunción del principio de que la norma tiene hoy carácter policéntrico. La muy notable cohesión lingüística del español es compatible con el hecho de que la valoración social de algunas construcciones pueda no coincidir en áreas lingüísticas diferentes. No es posible presentar el español de un país o de una comunidad como modelo panhispánico de lengua. Tiene, por el contrario, más sentido describir pormenorizadamente las numerosas estructuras que son compartidas por la mayor parte de los hispanohablantes, precisando su forma, su significado y su

\footnotetext{
${ }^{2}$ Para una caracterización de los dialectos españoles, véase Moreno Fernández (2009). En cuanto a la división de los dialectos del español, los tratados de dialectología, pero sobre todo las obras académicas, suelen incidir en las diferencias entre el español de España y el de América. A pesar de eso, se ha insistido en que dentro de estos territorios también existen diferencias relevantes, lo cual ha llevado a algunos autores a hablar del español en América y no de América. Para una síntesis del español en América, también puede consultarse: Ramírez Luengo (2007) y Aleza y Enguita (2010).

${ }^{3}$ Sobre la necesidad de incrementar y homogeneizar la información dialectal del diccionario académico, véase Fajardo (2011). De ahora en adelante, las obras académicas señaladas (y las que mencionaremos sobre el catalán) se citarán, por razones prácticas, por medio de sus siglas, con la referencia correspondiente al volumen y/o página.
} 
estimación social, y mostrar separadas las opciones particulares que pueden proceder de alguna variante, sea del español americano o del europeo. Cuando estas opciones resultan comunes, y hasta ejemplares, en áreas lingüísticas específicas, deben ser descritas como tales. Obrar de este modo no solo no pone en peligro la unidad del español, sino que contribuye más bien a fortalecerla, y ayuda a comprender su distribución geográfica de forma más cabal (NGLE: I, XLII).

Por otro lado, la valoración sobre los usos correctos e incorrectos se relativiza, ya que también se tienen en cuenta las variedades de uso, los registros en que se puede utilizar la lengua. Así pues, al lado de las valoraciones sobre el prestigio social de una forma gramatical determinada, se hacen consideraciones sobre su adecuación al discurso formal o informal, a la lengua oral o escrita o al propósito comunicativo (NGLE: I, XLII).

\subsection{El caso del catalán}

A pesar de su larga producción escrita y de la aparición de diversos tratados gramaticales durante el siglo XVIII y XIX, las circunstancias políticas han postergado a principios del siglo XX la codificación gramatical del catalán (Segarra, 2006). Bajo el auspicio institucional y académico del Institut d'Estudis Catalans (IEC), se encarga al filólogo Pompeu Fabra la elaboración de la normativa catalana (Ginebra y Solà, 2007). Esta labor no es nada fácil ya que se enfrenta a dos problemas básicos: a) la situación sociolingüística de la lengua, sin un estado detrás, sin el estatus de cooficial y con una fuerte presión de la lengua políticamente dominante, el español; y b) la variación dialectal de la lengua, repartida geográficamente, dentro del estado español, por las actuales comunidades autónomas de Cataluña, Valencia y las Islas Baleares, y una franja limítrofe oriental de Aragón; dentro del estado francés, por la región de los Pirineos Orientales; dentro del estado italiano, por la ciudad de Alguer, en la isla de Cerdeña; además de ser la lengua oficial en el pequeño estado de Andorra ${ }^{4}$.

En 1913 aparece la ortografía oficial y en 1918 la gramática, cuya edición definitiva es la de 1933. Al lado de estos tratados gramaticales, Pompeu Fabra publica en 1932 un diccionario, que es el punto de referencia de los usuarios de la lengua tanto por su interés léxico como por su información gramatical, complementaria a menudo de los tratados aparecidos. A partir de la segunda edición (1954), el IEC reconoce oficialmente este diccionario. La codificación fabriana se ha divulgado sobre todo gracias a sus epígonos, que a través de publicaciones de tratados gramaticales, de manuales o con su labor como correctores editoriales han conseguido consolidar el modelo. De hecho, el IEC no tiene apenas incidencia pública hasta la década de los $80 \mathrm{y}$ sobre todo en los 90, cuando publica diversos documentos normativos y realiza la

\footnotetext{
${ }^{4}$ Para una caracterización de los dialectos catalanes, véase Veny (1991). La división básica de los dialectos catalanes permite en principio la distinción de dos grandes bloques: el catalán oriental y el catalán occidental. Dentro del catalán oriental, se incluye: el catalán septentrional (zona francesa), el catalán central (gran parte de la zona este de Cataluña), el balear (Islas Baleares) y el alguerés (ciudad de Alguer). Dentro del catalán occidental: el noroccidental (zona oeste de Cataluña, incluida Tortosa, Andorra y franja de Aragón) y el valenciano (Comunidad Valenciana).
} 
actualización del diccionario, que es asumido por la misma institución y pasa a denominarse Diccionari de la Llengua Catalana (cf. Segarra, 2006). Este diccionario cuenta actualmente con una segunda edición, publicada en 2005, y el IEC tiene en proceso de elaboración la Gramàtica de la llengua catalana (GLC), que cuenta con una versión provisional en línea, que ofrece información sobre fonética y fonología, ortografía, morfología y formación de palabras, pero todavía no se puede acceder a los contenidos sobre sintaxis.

En la introducción de esta nueva gramática, como pasaba en las obras de referencia del español, también hay unas líneas programáticas que inciden en la importancia de la variación lingüística:

Aquesta gramàtica representa la institucionalització i la integració en una sola imatge de la llengua comuna d'aquelles propostes normatives que, seguint l'esperit de l'obra fabriana, hom havia adaptat a les peculiaritats de territoris altres que el Principat $i$ grans varietats dialectals altres que el català central en què, en bona mesura, es basava aquella obra. Adaptacions elaborades sigui mitjançant descripcions gramaticals, sigui per la pràctica dels escriptors, traductors, redactors del subàmbit lingüístic. Aquesta integració, que és una opció ben meditada, ens mena a una proposta normativa que hom pot qualificar d'unitària en la diversitat. Aquesta opció no és en cap cas contradictòria, no és en cap cas regressiva ni és en cap cas una iniciativa isolada en el concert de la institucionalització de les llengües, i és de bon tros preferible a la perversió que representaria qualsevol conat de promoure una pluralitat de normes aillades o juxtaposades. Aquesta integració, ben entès, no és pas una invitació a l'aliatge indiscriminat de formes lingüístiques, sinó el reconeixement en peu d'igualtat de modalitats lingüístiques coherents emanades d'un tronc comú. Aquest reconeixement, d'altra banda, no és obstacle per a la proposta d'un model convergent que cada part de la comunitat lingüística i cadascú dins aquestes parts sabrà gestionar adequadament $\mathrm{i}$ al ritme que els serà de més bon menar $(G L C: 21)$.

Como indica la cita, este nuevo tratado pretende consolidar el modelo de Fabra, respetuoso con la variación dialectal, pero también consolida la aplicación y adaptación que han hecho sus epígonos en las diferentes zonas geográficas (Ginebra y Solà, 2007: 239-284; Alomar, 2006; Ferrando, 2006). Por otro lado, como en la NGLE, también se insiste en orientaciones relacionadas con el registro lingüístico:

Quan s'escau, l'àmbit d'ús es precisa atenent al mode, al registre, al nivell de formalitat, corresponents: [...].

En determinats casos, cal complementar la descripció amb orientacions prescriptives. Així, la prescripció es planteja en termes positius quan es valida explícitament la variant en el model de referència o quan se li atorga un estatus jeràrquic en relació amb les altres o se'n restringeix l'àmbit d'ús: [...] (GLC: 24$)$.

Por tanto, tanto la variación dialectal como la variación estilística (registros) entran a formar parte de la descripción gramatical, que a su vez marca las pautas normativas pertinentes. 
A pesar de que esta aplicación de la normativa en el área lingüística catalana goza de un gran consenso, llama especialmente la atención la iniciativa llevada a cabo por el gobierno autonómico valenciano de crear en 1998 una institución académica que dictamine sobre temas normativos, la Acadèmia Valenciana de la Llengua (AVL) ${ }^{5}$. Aunque no nace como una institución que defiende un secesionismo lingüístico con el resto del catalán, sí que adopta un modelo lingüístico más particularista que satisface determinados sectores sociales que reivindican un mayor acercamiento a la modalidad dialectal valenciana. La publicación en 2006 de su Gramàtica Normativa Valenciana (GNV) confirma esta intención ${ }^{6}$. A pesar de todo, las diferencias normativas con las propuestas del IEC, como tendremos ocasión de ver más abajo, son escasas, pero cabe mencionar un aspecto importante: mientras las academias americanas se han asociado con la española y publican conjuntamente, la AVL es completamente independiente del IEC, e incluso mantiene un cierto distanciamiento con el IEC, a pesar de que paradójicamente comparten algunos académicos.

\section{LAS PROPUESTAS NORMATIVAS Y LA VARIACIÓN LINGÜÍSTICA}

En este apartado analizaremos qué aspectos de la variación dialectal tienen cabida en el modelo normativo. Como ya hemos advertido más arriba, solo nos ocupamos de las propuestas que afectan a la lengua escrita, aunque actualmente los límites entre la lengua escrita y la lengua oral son cada vez más difusos, ya que la lengua escrita tradicionalmente ha condicionado el modelo estándar oral, de la misma manera que en la actualidad la importancia de la lengua hablada en los medios de comunicación, con la posible variación dialectal que puede conllevar, acaba (o puede acabar) determinando el cambio del modelo estándar escrito.

\subsection{Caracterización del modelo normativo}

El modelo normativo tradicional del español se ha descrito como unitarista y monocéntrico. Es decir, un modelo que tiene un solo estándar, con denominaciones equivalentes como lengua general, lengua común o lengua neutra, basado en el español peninsular del centro y norte de España. Y con un centro de difusión, la RAE.

Esta concepción inicial unitarista y monocéntrica ha condicionado no solo la codificación ortográfica y gramatical en general, sino también, por parte de los usuarios de la lengua, la valoración más o menos positiva de su propia variedad dialectal. No es extraño, pues, que soluciones lingüísticas que se apartan de este modelo tradicional hayan sido estigmatizadas o que, aunque hayan sido reconocidas académicamente como

\footnotetext{
${ }^{5}$ Se trata de la Lei 7/1998, de 16 de septiembre, de la Generalitat Valenciana, de Creación de la Acadèmia Valenciana de la Llengua [1998/7973]. Se puede consultar también en AVL (2002).

${ }^{6}$ La publicación de esta gramática fue acompañada por la aparición del Diccionari Ortogràfic $i$ de Pronunciació del Valencià (2006), que ha recibido muchas críticas por su carácter más dialectalizante. Véase Pradilla (2008: 35-63) y Senz, Minguell y Alberte (2011).
} 
aceptables, cuenten todavía con un prejuicio consciente o inconsciente ${ }^{7}$. Tampoco nos debe extrañar que la apertura del modelo normativo hacia el denominado panhispanismo haya venido precedida de continuas reivindicaciones, sobre todo desde el área americana, hacia un modelo polimórfico y policéntrico, que lejos de contribuir a la fragmentación de la lengua ayudaría a una mayor integración ${ }^{8}$. Esto es, un modelo que acepte alternativas normativas y cuya responsabilidad emane de más de un centro. De hecho, es lo que teóricamente se pretende con la publicación del DPD y la NGLE y con la colaboración asociada de las Academias de la Lengua Española.

El modelo normativo del catalán, a pesar del peso que se le concede a la zona del catalán central, que tiene como referente Barcelona, parte de la necesidad, para que sea aceptado, de que los hablantes de los diferentes dialectos se vean identificados. En este sentido, podemos decir que su concepción se puede resumir con tres conceptos: monocentrismo, composicionalidad y polimorfismo. Ginebra y Solà (2007: 105) han sintetizado claramente el valor de estos conceptos $^{9}$ :

Fabra defensava que la normativa fos monocèntrica, és a dir que emanés d'un centre codificador únic, l'IEC. Aquesta normativa és composicional: consta d'elements aportats per diferents varietats geogràfiques, que són en principi vàlids i preceptius per a tots els usuaris. I és també polimòrfica: en diversos punts del codi hi ha més d'una forma plenament normativa, i aquestes formes divergents en principi o en la pràctica són vàlides només o especialment per als parlants que les tenen com a pròpies.

Pero, como ya hemos advertido más arriba, con la creación reciente de la Acadèmia Valenciana de la Lengua, se cuestiona el monocentrismo inicial, ya que hay más de un centro codificador, y aunque esta institución mantiene la base de la codificación fabriana, incrementa el polimorfismo tomando como referente la variedad dialectal valenciana.

Así pues, aunque el modelo español y el catalán parten de una concepción diferente (unitarista, el español; composicional, el catalán), comparten el compromiso de integrar el polimorfismo, pero mientras en catalán es ya una tradición, en español se abre una nuevo camino, al menos de manera oficial.

\subsection{Polimorfismo y variación dialectal}

En este apartado nos ocuparemos de analizar y contrastar hasta qué punto, desde la perspectiva de la variación dialectal, las propuestas normativas vigentes en español y

\footnotetext{
${ }^{7}$ Veánse, por ejemplo, las reflexiones hechas por Rojas (2001), López García (2010) y Ramírez Gelbes (2011), desde la Argentina, por Barrios (2011), desde Uruguay, o Díaz Salgado (2011), desde España.

${ }^{8}$ Por ejemplo, véanse las reflexiones de Demonte (2001), Rivarola (2001), Lara (2011), Senz, Minguell y Alberte (2011) y Moreno Cabrera (2011). Es seguramente demasiado tarde para consensuar un modelo composicional, como proponía Lope Blanch (2001), según el cual la norma hispànica «ideal» debería integrar las soluciones más generalizadas y cultas de los diferentes dialectos, y podría coexistir con normas más particulares, las nacionales.

${ }^{9}$ Sobre los criterios de codificación fabriana, pueden consultarse las aportaciones de Segarra (1985), Bibiloni (2004: 113-126) y Ginebra y Solà (2007).
} 
en catalán proponen alternativas que justifican el polimorfismo apuntado ${ }^{10}$. Estudiaremos el polimorfismo en el plano ortográfico, en el plano morfológico y en el plano sintáctico. Pero, antes de exponer los diferentes casos, es necesario insistir en un hecho que, en el caso concreto de la $N G L E$, de algún modo puede condicionar la consideración de determinadas alternativas lingüísticas como propiamente normativas o no. Nos referimos a las constantes alusiones a los registros en que se usan determinadas soluciones, lo cual puede ir a favor de la inclusión del fenómeno como dentro de la norma o más bien puede excluirlo. Entendemos, pues, que, de acuerdo con la introducción a la $N G L E$ y al $D P D$, forman parte de la norma aquellos usos que, en la redacción de estas obras, se califican como estándar, cultos, formales o escritos, o que simplemente en la descripción no reciben valoración porque se consideran propios de la norma. En el lado opuesto, tendríamos los que se califican de usos conversacionales, coloquiales, rurales, vulgares, calcos o reciben restricciones como «ocasionalmente»o «no se recomienda». Ahora bien, puede haber problemas sobre la interpretación de si es normativo o no en casos en que se describe la solución aludiendo al carácter oral, hablado o popular, ya que estas atribuciones pueden entrar en conflicto con las de conversacional o coloquial, pero también con las de estándar oral, y, por extensión, estándar escrito. Por lo tanto, podría ocurrir que esta ambigüedad en algunos casos no permitiera al lector dilucidar qué es normativo o qué no lo es, o incluso puede llevar a una interpretación diferente de la misma solución lingüística. En nuestro caso, nos ocuparemos de los fenómenos que se califican como estándar, cultos, formales o escritos, y, siempre que no tengan una restricción aclaratoria, de los usos caracterizados como oral, hablado o popular.

Por otra parte, cabe apuntar también que la referencia al polimorfismo en las obras españolas no siempre va acompañada de una localización dialectal precisa, ya que se utilizan expresiones como «en algunos países», «en ciertas regiones», «en gran parte de», lo cual dificulta la descripción que pretendemos llevar a cabo ahora, pero también, como analizaremos más abajo, su aplicación por parte del usuario.

\subsubsection{La ortografía}

La ortografía es posiblemente el ámbito de la lengua escrita donde más cuidado tienen las obras académicas a la hora de proponer alternativas. Tradicionalmente, la ortografía se ha asociado al concepto de corrección, con la alusión constante a las denominadas «faltas de ortografía», y representa el símbolo de la unidad de una lengua y de la diferenciación respecto a otras. No es raro tampoco que variedades dialectales reconocidas filológicamente como pertenecientes a una misma lengua, por motivos

${ }^{10}$ Ya podemos encontrar una primera aproximación a las novedades de las obras gramaticales del español en los trabajos de Aleza $(2006 a, 2010,2011 a)$, con una atención especial a la variación dialectal americana, y Gómez Torrego (2011). En el caso del catalán, la difusión de un modelo estándar con las alternancias normativas adaptadas al ámbito dialectal correspondiente ya es una tradición fuera de Cataluña desde la misma aceptación de la codificación fabriana (Ginebra y Fabra, 2007: 239-252; Alomar, 2006; Ferrando, 2006). Para una descripción de las numerosas alternativas formales que se pueden llegar a dar por razones ideológicas en el modelo catalán del área valenciana, véase Mas (2008).

NORMAS. REVISTA DE ESTUDIOS LINGÜÍSTICOS HISPÁNICOS, NÚMERO 3 (AÑO 2013):

http://www.uv.es/normas

(ISSN 2174-7245) 
políticos acaben adoptando soluciones ortográficas diferentes para conseguir una secesión (Nadal, 2006) ${ }^{11}$. Aun teniendo en cuenta estas reservas, tanto el español como el catalán han adoptado soluciones ortográficas polimórficas.

En el caso del sistema vocálico, estas afectan a la acentuación. En español, el hecho de que la pronunciación americana sea diferente de la española en determinadas palabras justifica la aceptación de dos escrituras. Por tanto, a la acentuación en España de palabras como bumerán, béisbol, chófer, cóctel, fútbol, vídeo; biosfera, estratosfera, etc. (acabadas en -sfera); artroscopia, endoscopia, etc. (acabadas en -scopia); angioplastia, rinoplastia, etc. (acabadas en -plastia); se une la solución más extendida en América: búmeran, beisbol, chofer, coctel, futbol, video; biósfera, estratósfera, etc.; artroscopía, endoscopía, etc.; angioplastía, rinoplastía, etc. ${ }^{12}$. En catalán, la doble acentuación se da según la pronunciación abierta o cerrada de la vocal $e$ en palabras como: cafè/café, cinquè/cinqué, francès/francés, conèixer/conéixer, parèixer/paréixer, etc. Mientras es costumbre en el área valenciana, aunque también puede usarse la otra opción, la acentuación cerrada (café), en el resto del catalán se adopta exclusivamente la acentuación abierta (cafè). A pesar de esto, es invariable la acentuación en palabras más gramaticalizadas, pero también con diferente pronunciación: què (pronombre relativo o interrogativo), perquè (conjunción) o en el topónimo València. Esta alternativa normativa se recoge tanto en la $G L C$ (383) del Institut d'Estudis Catalans como en la GNV (47-48) de la Acadèmia Valenciana de la Llengua.

En cuanto al sistema consonántico del español, el primer aspecto destacable desde un punto de vista de la variación dialectal son las dobles denominaciones de las letras: $b, v, w$. La nueva ortografía (OLE: 70) apunta que en España se llaman respectivamente be, uve y uve doble. En cambio, en América puede adoptar nombres diversos, según los países: be, be larga, be grande, be alta; uve, ve, ve corta, ve chica o chiquita, ve pequeña, ve baja; ve doble, doble ve, doble uve, doble $u^{13}$.

${ }^{11}$ Esta situación, sobre todo hasta la creación de la AVL, la padece, aunque con una repercusión mínima, el catalán en la zona valenciana (cf. Mas, 2008).

${ }^{12}$ Este fenómeno tiene un atención mínima en la Ortografía de la Lengua Española (OLE: 211) y es abordado en las entradas correspondientes del $D P D$, que recoge algunos otros casos, con una extensión dialectal más limitada: Amazonia/Amazonía, Jacarandá/Jacaranda, Rumanía/Rumania, sóviet/soviet. Para una síntesis, véase Aleza (2011a: 42) y Gómez Torrego (2011: 69); para una posición crítica, véase Martínez de Sousa (2011: 667). Otro cambio, en principio, basado en la distribución dialectal, fue el que inicialmente adoptó el $D P D$ en relación con palabras tradicionalmente escritas con acento como guión, riáis, etc. La pronunciación como hiato en España y América del Sur y la pronunciación como diptongo en México y Centroamérica dio paso a la propuesta doble del DPD: guión/guion. Aunque finalmente en la OLE $(224,231-236)$ se propone que los monosílabos no se acentúan: guion, riais, etc., y solo se adopta una solución.

${ }^{13}$ El nombre de be larga/be corta es usual en la Argentina, Paraguay, Uruguay, Chile, Colombia, Venezuela, Guatemala, Cuba y República Dominicana. México, Centroamérica y los países andinos prefieren be grandel ve chica, chiquita o pequeña. También merece destacarse el hecho de que, cuando una de estas denominaciones alternativas puede ser sospechosa de interferencia lingüística, la $O L E$ lo valora como calco: este es el caso de doble u para México y países de Centroamérica, y el de be alta y ve baja para España, donde se considera un catalanismo; por lo tanto, a pesar de que este último caso en América (la Argentina y Venezuela) se dé como bueno, no se admite en España. 
Asimismo, por el hábito de escritura distinto en el español europeo y en el americano, se justifica una grafía diferente en palabras como las siguientes. La primera solución sería la habitual en España y la segunda la más usada en América (OLE: 75123): hiedra/yedra, hierba/yerba, hierbal/yerbal, hierbabuena/hierbabuena, jersey/yérsey o yersi, pijama/piyama, Méjico/México (en esta y en Tejas/Texas, la normativa prefiere la solución americana como general), chamullar/chamuyar, cholla/choya.

Más restringida es la extensión que se concede a los participios derivados de escribir, ya que pueden alternar la forma adscrito y adscripto (OLE: 188). La solución conservadora con -pt- (descripto, inscripto, prescripto, suscripto, etc.) se considera «de uso normal», especialmente en la Argentina, Paraguay y Uruguay.

En el caso del catalán, también el abecedario conoce dobles denominaciones según la variación dialectal. Las letras $f, l, m, n, r, s$ pueden adoptar dos denominaciones: las más extendidas en el ámbito educativo son efa, ela, ema, ena, erra, essa; aunque en la lengua hablada de parte de Cataluña (catalán noroccidental) y en la Comunidad Valenciana se usan efe, ele, eme, ene, erre, esse. Estas diferencias de uso han repercutido en el tratamiento diferente que conceden las gramáticas normativas: mientras la $G L C$ (357) del IEC da preferencia a la primera y minimiza la segunda, sin detallar que es una variación dialectal, la $G N V(36)$ de la AVL otorga preferencia a la segunda, y apunta, como una observación, y sin detalles dialectales tampoco, las variantes con $a$ final.

En el consonantismo, el catalán solo conoce la alternativa $\mathrm{tll} / \mathrm{tl}$ correspondiente a palabras como ametlla/ametla, vetllar/vetlar, motlle/motle, etc. Esta doble opción responde a una diferente pronunciación según la variación dialectal: en Cataluña, suena como palatal lateral (duplicada o simple), y en Baleares y la Comunidad Valenciana como lateral no palatalizada (duplicada o simple). Pero cabe decir que la $G L C$ (367), aunque da como posibles las dos soluciones, no especifica la distribución dialectal; por el contrario, la $G N V$ (45) no recoge la solución catalana tll (ametlla).

\subsubsection{La morfología}

En el plano morfológico, el polimorfismo se hace más evidente. Pero, como tendremos ocasión de ver a continuación, es mucho más importante en catalán que en español. Veamos los casos más relevantes.

\subsubsection{En las categorías no verbales}

En el caso del español, si analizamos en primer lugar los aspectos relacionados con la flexión nominal, podemos observar la aceptación de un género diferente en determinadas palabras a causa de la variación dialectal (NGLE: I, 91-122). Este es el caso, por ejemplo, de radio, que se usa como masculino, en México, Centroamérica, la zona de las Antillas y del Caribe, y la zona andina, frente al femenino del resto; también tienen un uso masculino en gran parte de América: dinamo, lente, sartén y sauna, frente al femenino de España. En cambio, bikini prefiere el género femenino en la zona del 
Río de la Plata, y piyama también en México, Centroamérica, las Antillas y el Caribe continental. Tanto una como la otra suelen ser masculinas en el resto. En la zona americana, también predomina el género femenino, frente a la solución de España, en palabras como: armazón, maratón y tanga. Llama la atención, en cambio, que el uso extendido de la forma femenina de calor en el área andina, de Río de la Plata y de Andalucía, no se considere normativo (NGLE: I, 113). Por otro lado, hay más permisividad en el cambio de género en algunas palabras en el español de América que en el europeo: fiscal/fiscala, juez/jueza; aunque en algún caso, como bebe/beba, su aceptación se reduce a determinadas zonas americanas (Antillas, área andina y del Río de la Plata).

En cuanto a la formación del plural, en las palabras terminadas en $-u ́$ de origen extranjero, al lado de la solución general en $-s$, también se acepta el plural en -es (champú > champúes), propio de la zona del Caribe continental, el área andina y el área del Río de la Plata (GNLE: I, 134).

En cuanto a las formas de los pronombres personales, el aspecto más relevante es la aceptación normativa del voseo. Pero, a pesar de ser una solución extendida por gran parte de América (parte de México, Centroamérica, Antillas, Caribe continental, área andina, área rioplatense y Chile), el tradicional rechazo de esta forma pronominal, en lugar de la forma tú, ha repercutido en su consideración social y, como uso normativo, entiéndase culto y escrito, queda restringida a la zona rioplatense ${ }^{14}$. Por el contrario, la forma correspondiente del plural, ustedes, general en América (y también habitual en la lengua popular de Andalucía occidental y Canarias), sustituye a la forma europea vosotros, como solución también normativa (DPD: 659; NGLE: I, 192).

Esta redistribución pronominal tiene también consecuencias en las formas de los posesivos, ya que, frente a la solución vuestro, correspondiente al pronombre vosotros, la norma americana (y, en principio, también la parte occidental de Andalucía y Canarias) opta por suyo o de él: vuestro problema / el problema suyo (NGLE: I, 1339).

En los deícticos demostrativos y locativos, la variación dialectal permite la coexistencia, según las zonas, de dos sistemas: el ternario (este, ese, aquel; aquí, ahí, allí) y el binario (este, ese; aquí, ahí / acá, allá). Frente al mantenimiento del sistema ternario, característico del español peninsular, también se considera estándar el sistema binario. En el caso de los locativos, el binario es de uso preferente en la mayoría de los países americanos y en Canarias. En el de los demostrativos, el binario predomina sobre todo en el área rioplatense, andina y chilena (NGLE: I, 1280-1281, 1314).

En los cuantitativos, podemos destacar, por un lado, la aceptación de la forma harto en la lengua estándar de Chile, los países andinos y México, en contextos similares en el resto del español a los de mucho y muy: hartos hijos, harto modestas, La he buscado harto (NGLE: I, 1386). Y por otro lado, la no aceptación de la concordancia del cuantificador medio, que tiene una gran extensión en la lengua popular de América

${ }^{14}$ Véanse los comentarios que sobre este hecho aparecen en el DPD (672-676) y en la NGLE (I: 210-213), y en Cartagena (2001). A pesar de la aparente normalidad del voseo en el modelo normativo de la zona rioplatense, diversos autores han denunciado que continúa hasta cierto punto estigmatizado en los escritos formales y manuales educativos (cf. López García, 2010; Barrios, 2011). 
(México, Centroamérica, Venezuela, Chile y área rioplatense) y parte de España (noroeste y Canarias): media dormida, medios tontos (NGLE: I, 1395).

En cuanto a los aspectos morfológicos del catalán, en primer lugar cabe mencionar el comportamiento de las palabras que adoptan por derivación el sufijo -ista. En estas, aunque existe variación de género (artistelartista) en los dialectos noroccidental y valenciano frente al resto del catalán, las gramáticas académicas (GLC: 107-108; GNV: 342-343) insisten en que en la lengua estándar escrita la única solución es la invariable -ista. A pesar de eso, la GNV sugiere, si bien como solución secundaria, la posibilidad también de variación de género.

En la formación del plural, la variación dialectal permite una doble posibilidad en las palabras acabadas en $-s c,-s t,-x t,-s p,-i g$, ya que existen zonas del valenciano y de las Islas Baleares donde se conservan los plurales más antiguos en $-s$ (boscs), al lado del plural más moderno en -os (boscos), solución preferente en el resto del catalán. A pesar de este polimorfismo, cabe destacar que mientras la GLC (120-121) propone en primer plano las formas en $-O s$, la $G N V(103,121)$ ubica en primer lugar las formas en-s. Un caso similar se produce con los plurales de los sustantivos llanos terminados en $-e$ : home, jove, marge, etc., que pueden hacer el plural recuperando la $n$ etimológica (hòmens) o añadiendo simplemente una $-s$ (homes). La primera solución, más conservadora, que ha quedado restringida a la zona dialectal del catalán noroccidental, valenciano, zona de Tarragona y las Islas Baleares, aparece en segundo plano en la GLC (118), pero como preferente en la $G N V$ (101). Por lo tanto, aunque ambas gramáticas aceptan el polimorfismo, se prioriza la solución dialectal más próxima.

En lo referente a los pronombres personales, el pronombre átono de segunda persona de plural en la forma vos, la GLC (133) no lo considera adecuado en posición proclítica para los usos formales de la lengua escrita (vos ha demanat), y propone us (us ha demanat); en cambio, la GNV (172), atendiendo al uso valenciano, prefiere la solución vos, al lado de la solución $u s^{15}$.

Por su parte, los posesivos también conocen una doble forma normativa como consecuencia de la variación dialectal. La GLC (142-143) considera igualmente aceptables las soluciones consonantizadas meva, teva, seva (predominan en la zona del catalán oriental) y las soluciones no consonantizadas теиа, теиа, sеиа (predominan en el catalán occidental y balear). Ahora bien, este trato de igualdad no se produce en la $G N V$ (136), donde las formas consonantizadas, que han producido en algunos sectores sociales reaccionarios valencianos connotaciones catalanistas, se minimizan con una observación puntual y, desde un punto de vista dialectal, imprecisa («en altres parlars»).

Los deícticos demostrativos, los locativos y también los neutros muestran un sistema binario o ternario según el área dialectal. Así la mayor parte del catalán manifiesta un sistema binario (aquest, aquell; aquí, allílallà; això, allò); mientras que el área valenciana y parte del noroccidental mantienen el sistema clásico ternario, pero con las formas primera y segunda del demostrativo reducidas (este, eixe, aquell; ací, aquí, allílallà; açò, això, allò). La normativa de la GLC (141-142) acepta tanto el sistema

${ }^{15}$ Cabe señalar que el documento del IEC (1999: 20), en el que se realiza una propuesta del estándar oral, sí que se acepta esta posibilidad en el ámbito dialectal correspondiente.

NORMAS. REVISTA DE ESTUDIOS LINGÜÍSTICOS HISPÁNICOS, NÚMERO 3 (AÑO 2013):

http://www.uv.es/normas

(ISSN 2174-7245) 
binario como el ternario, pero en el caso del ternario prefiere en los registros formales las soluciones reforzadas (aquest, aqueix, aquell) a las reducidas (este, eixe, aquell). Esta puntualización no se da en la $G N V$ (132), que, aunque las acepta las dos por igual, en la redacción de la gramática usa exclusivamente la forma reducida de acuerdo con el uso general de la lengua hablada. También es una novedad con transcendencia normativa y no prevista por la $G L C$, la aceptación, por parte de la $G N V$ (135), de ahí como la forma prototípica, en lugar de aquí, para el segundo grado de los adverbios locativos (ací, ahí, allílallà) ${ }^{16}$.

Los cuantificadores también reflejan cierto polimorfismo en los tratados gramaticales. El caso más evidente es el de los numerales. La GLC (147), al lado de las formas que considera generales vuit (8) disset (17), divuit (18), dinou (19), vuitanta (80), tolera formas que califica de particulares: las valencianas huit (8), dèsset (17), díhuit (18), dèneu o dènou (19), huitanta (80); y las de las Islas Baleares desset (17), devuit (18), denou (19). Por su parte, la $G N V$ (142) da preferencia a las formas valencianas, presenta como segunda opción las generales -por ejemplo, huit (o vuit) - e ignora las baleares.

Otros cuantificadores que podemos destacar son molt y gaire, con el mismo valor pero usados en contextos sintácticos diferentes. El primero se usa en contextos afirmativos; el segundo se reserva en la lengua general y estándar a los contextos negativos, interrogativos y condicionales, pero actualmente es desconocido en el habla popular valenciana. Esto ha determinado que la $G N V$ (161) también acepte la forma molt en los contextos asignados en principio a gaire ${ }^{17}$. Por otra parte, en las Islas Baleares se usan también como formas estándar los indefinidos qualcun y qualque equivalentes de algun (Hi ha qualques coses), y como invariable gaire (No té gaire cotxes) (GLC: 152-154).

\subsubsection{En la categoría verbal}

Los principales aspectos que afectan a la morfología del verbo en español son los vinculados al voseo verbal, al uso de ustedes en lugar de vosotros, y a la distinción entre el pretérito perfecto simple y el pretérito perfecto compuesto.

En el caso del voseo verbal, a pesar de la variación de formas que se distribuyen por gran parte de América y del hecho de aparecer en tiempos verbales diversos (presente de indicativo, pretérito perfecto simple, presente de subjuntivo, imperativo, y en algunos países incluso en el futuro y en el pretérito imperfecto) (cf. NGLE: I, 210216), la norma de la conjugación verbal es muy restrictiva, ya que solo acepta las formas del área rioplatense $\mathrm{y}$, aun así limitándose a los tiempos de presente de indicativo (amás, temés, partís) y del imperativo (amá, temé, partí) (cf. NGLE: I, 253$325)$.

\footnotetext{
${ }^{16}$ Se da la circunstancia de que incluso en la propuesta de estándar oral del IEC (1999: 19), la forma ahí solo se acepta en los registros orales informales.

${ }^{17}$ Esta divergencia tiene también el precedente de la propuesta del estándar oral del IEC (1999: 20), donde se admite este uso restringido a la zona valenciana.
} 
En cuanto al uso de ustedes por vosotros, que supone la eliminación de la forma de segunda persona del plural de todos los tiempos, la cual ha sido asumida por la tercera persona (amáis > aman, amabais > amaban, etc.), es la solución normativa en el español americano y, en principio, también en Andalucía occidental y en Canarias (NGLE: I, 192) ${ }^{18}$.

Respecto a la distinción entre el pretérito perfecto simple (amé) y el pretérito perfecto compuesto (he amado), la circunstancia de que, en España y en América, haya zonas tanto de distinción de la oposición temporal (o aspectual) como de neutralización a favor en general de la forma simple, se corresponde con una norma que acepta las dos soluciones (NGLE: I, 1721-1722).

Mucha más variación presenta la morfología verbal catalana, lo cual también se ve reflejado en la gramática académica. Efectivamente, la circunstancia de que las desinencias verbales sean una muestra clara de identidad y de separación respecto a otros dialectos ha hecho difícil la imposición de unas soluciones sobre otras, de manera que las gramáticas incluyen esta variación también como parte de la norma propia del área donde se produce (cf. Pérez Saldanya y Rigau, 2005). Así lo asume la GLC (§ 21.2), en la que el polimorfismo en la conjugación regular, a grandes rasgos, es el siguiente: a) en Catalunya: $1 .^{\mathrm{a}}$ persona del presente de indicativo (canto), presente de subjuntivo (canti, cantis, ...; temi, temis, ...), imperfecto de subjuntivo (cantés, cantessis, ...), verbos incoativos (presente de indicativo: pateixo, pateixes, ...; presente de subjuntivo: pateixi, pateixis, ...); b) en la Comunidad Valenciana: 1. ${ }^{a}$ persona del presente de indicativo (cante), presente de subjuntivo (cante, cantes, ...; tema, temes, ...), imperfecto de subjuntivo (cantara, cantares, ...; cantés, cantesses, ...), verbos incoativos (presente de indicativo: patisc, pateixes/patixes, ...; presente de subjuntivo: patisca, patisques, ...); c) en las Islas Baleares: 1. ${ }^{a}$ persona del presente de indicativo (cant), presente de subjuntivo (canti, cantis, ...; temi, temis, ...), imperfecto de subjuntivo (cantàs, cantassis, ...), verbos incoativos (presente de indicativo: patesc, pateixes, ...; presente de subjuntivo: patesqui, patesquis, ... $)^{19}$.

Una aplicación más restrictiva de la variación verbal catalana es la que nos ofrece la $G N V$, la cual no incluye explícitamente en los modelos de conjugación el polimorfismo dialectal, aunque sí que lo precisa en diferentes apartados (GNV: 252254). Esta gramática, en su línea más particularista, da preferencia asimismo en los verbos incoativos a la solución con incremento en -ix- (patix), más próxima al oral, y no

${ }^{18}$ La $N G L E(I, 193)$ advierte que, en la zona andaluza, la presión de los medios de comunicación hace avanzar el uso de vosotros sobre ustedes.

${ }^{19}$ No es nuestro propósito hacer una descripción exhaustiva de las variantes, pero cabe citar también por su carácter identificativo: a) las desinencias de 1 a $^{\mathrm{a}}$ y 2 . $^{\mathrm{a}}$ persona del plural del presente de indicativo en balear: cantam, cantau; b) los participios en valenciano terminados en -it (oferit, establit, etc.) frente a la solución más extensa en -ert (ofert, establert, etc.); c) en el verbo ser: la forma balear de primera persona del presente de indicativo (som en lugar de sóc); la segunda persona del presente de indicativo del valenciano (eres en lugar de ets); y el participio estat para ser y para estar, como solución culta en los textos escritos formales (usada popularmente, por conservadurismo, en las Islas Baleares), frente a la solución diferenciadora, sigut para ser y estat para estar, más extendida en la lengua oral de Cataluña y de la Comunidad Valenciana, y con transferencia cada vez más habitual en la escrita. 
a la solución en -eix- (pateix), que era más habitual en la lengua escrita y convergía con el catalán oriental.

\subsubsection{La sintaxis}

A pesar de que las diferencias sintácticas dentro de una misma lengua no sean tan habituales, tanto el español como el catalán presentan también muestras de variación. Por razones de espacio, nos centraremos en las más significativas con el fin de analizar la valoración de las obras académicas de referencia ${ }^{20}$.

Los gramáticos suelen ser más reacios a aceptar el polimorfismo como consecuencia de la variación sintáctica. De hecho, el primer caso que nos ocupa, las oraciones impersonales, son una muestra evidente de esto. En español, continúa condenándose la concordancia del verbo haber con el teórico complemento directo, en las formas hayn, habian, hubieron, hayan, aunque en casos como habian la propia NGLE (II: 3063) reconozca que «se documenta en abundancia» en textos formales. De hecho, sobre todo en las formas de pasado, su uso está muy generalizado en América y en la zona del este y sureste de España (Gómez Molina, en prensa). Sin embargo, se admite la concordancia y la falta de concordancia en las construcciones con se, cuando el verbo va en presente y el SN no lleva determinante: Se vende pisos / Se venden pisos. Si se modifica el tiempo o lleva un determinante se prefiere la solución concordada: $S e$ alquilaron varias habitaciones; aunque para la solución no concordada se reconoce que «en algunos países empieza a ser aceptada la impersonal en esos contextos» (NGLE: II, $3099)^{21}$.

Esta alternancia no es un fenómeno exclusivo del español, sino que se documenta en otras lenguas, como es el caso del catalán. En esta lengua, tradicionalmente también se proscribe la concordancia del verbo haver-hi, si bien al lado de la solución conservadora sin concordancia, que podemos encontrar en las zonas dialectales del

${ }^{20}$ Otros casos en que podemos relacionar variación y norma polimórfica en español pueden ser, por ejemplo: el uso particular de los posesivos en las zonas mexicana, centroamericana y andina (NGLE: I, §18), las diferencias de régimen verbal preposicional entre España y América (para una síntesis de la norma, véase Aleza, 2011a: 69-73), la mayor frecuencia de perífrasis aspectuales o modales en América que en España (NGLE, II: $\S 28$ ), un mayor uso del verbo estar en América que en España (NGLE: II, 2823-2824) o los casos de queísmo y dequeísmo, no aceptados por la norma, pero muy presentes en la lengua oral (y también en la escrita, en el caso del queísmo) en todo el territorio, y de manera especial en América (NGLE: II, 3248-3256; Demonte, 2001; Bentivoglio, 2001; Moreno Fernández, 2009: 356, 378; Aleza, 2011b: 103-106; Gómez Molina, 2011). En el caso del catalán, se pueden citar los usos del artículo personal (en/el/Ø Pere), la concordancia del participio pasado con el pronombre clítico acusativo (A ella, ja l'he vista/A ella, ja l'he vist), algunas combinaciones pronominales (li'n>n'hi), usos pronominales de en y $h i$, las construcciones temporales en/al + infinitivo, o los usos sintácticos de ser y estar, entre otros (cf. Solà, 1994; Ginebra y Solà, 2007: 162-185).

${ }^{21}$ La observación de carácter geográfico de la $N G L E$ en este punto es totalmente imprecisa: «en algunos países». Entendemos que se debe de tratar de países americanos, tal y como apunta, por otro lado, Gómez Torrego (2011: 149). También se da el visto bueno, en zonas como México, Centroamérica, Caribe continental, Perú y Uruguay, a las discordancias que aparecen en construcciones impersonales del tipo: Habría que irnos (por habría que irse) o Es necesario lavarnos (por Es necesario lavarse) (NGLE: I, 1186).

NORMAS. REVISTA DE ESTUDIOS LINGÜÍSTICOS HISPÁNICOS, NÚMERO 3 (AÑO 2013):

http://www.uv.es/normas

(ISSN 2174-7245) 
balear, el noroccidental y el alguerés, tenemos la solución innovadora con concordancia, usual en la zona oriental de Cataluña y en la Comunidad Valenciana: Hi ha tres persones / Hi han tres persones. Esta variación también afecta a las construcciones impersonales con se (incluidas las pasivas reflejas) y las denominadas construcciones con verbo inacusativo (arribar, sortir, trencar-se, etc.), las cuales presentan una solución no concordada en el catalán noroccidental frente a la solución concordada y normativa del resto del catalán: S'ha portat tres coses / S'han portat tres coses; Ha arribat tres persones / Han arribat tres persones. A pesar de las reivindicaciones a favor del polimorfismo (Solà, 1994: 21-26; Pérez Saldanya y Rigau: 2005; Ramos, 2001; Ramos, 2002), de momento, la normativa del IEC y también la de la AVL (GNV: 305) continúan inamovibles en los registros formales ${ }^{22}$.

Otro fenómeno de interés son las alternancias en el régimen verbal entre acusativo y dativo. En español, el caso más significativo es el leísmo, con una variación diferente según el tipo de construcción. Adquiere una gran extensión su uso en las construcciones impersonales con se (en el español europeo y en zonas americanas como México, Centroamérica, Antillas y buena parte del área andina), y por ello se considera normativo (NGLE: I, 1220-1221, 2665): Se le vio ayer / Se lo/la vio ayer. También se acepta en España el leísmo de persona masculino singular, si bien su extensión es menor (español europeo: Castilla y parte de Aragón y Andalucía, y País Vasco): Yo le vi / Yo lo $v i$. Por el contrario, se rechaza el leísmo de persona femenino y el de persona plural, y el leísmo de cosa (NGLE: I, 1218-1220).

Diferentes de los casos tradicionalmente conocidos como leísmo, son aquellos en que la alternancia tiene una motivación etimológica o sintáctico-semántica. Se trata de verbos como creer, obedecer, escuchar, ayudar o servir, que en latín admitían un dativo; como animar, autorizar, convencer, obligar, entre otros, que presentan una estructura CD más un complemento preposicional; como hacer y dejar, que forman estructuras causativas; o como atender y telefonear ${ }^{23}$. El hecho de que estos verbos muestren alternancias acusativo / dativo tanto en zonas de España como en zonas americanas ha favorecido el polimorfismo de la norma: Yo no lo creo / yo no le creo; Le ha telefoneado; Lo ha telefoneado (NGLE: I, 1218-1224, 1247; NGLE: II, 2710-2712). También se manifiesta alternancia y permisividad normativa en los usos de los verbos

${ }^{22}$ Demonte (2001) ha hecho ver, refiriéndose al español, que el fenómeno de concordancia o falta de concordancia no se debe tratar como un defecto normativo, sino que responde a una de las opciones que tienen las lenguas o sus dialectos a la hora de manifestar este tipo de construcciones. Es lo que se conoce en lingüística generativista como «variación paramétrica». Por tanto, fenómenos como este u otros que se pueden explicar como opciones dentro de la variación paramétrica, para Demonte deberían ser aceptados.

${ }^{23}$ Véase también la síntesis de Aleza (2011b: 94-98)). Parece ser que el fenómeno se extiende a otros verbos donde es frecuente omitir el CD y reinterpretar el CI como acusativo en zonas de América y España: robar, pegar, abrir, disparar, preguntar, escribir, pagar y ganar. La norma, en este caso, solo admite la alternancia en el caso de robar (NGLE, II: 2710). Para el resto de estos verbos, véanse las entradas correspondientes del DPD y la entrada leísmo 4d, NGLE (II, 2711) y Gómez Torrego (2011: 136), donde prevalece el argumento de la imposibilidad de formar una pasiva sobre la simple aceptación de una variación no necesariamente vinculada al loísmo o al laísmo y con una extensión considerable. A pesar de esta valoración, en algún caso como pagar se produce la matización de que es «menos recomendable» (DPD: 481). 
aburrir, agradar, cansar, fascinar, molestar, preocupar, etc. Con estos verbos, cuando el sujeto actúa como un agente que ejerce un efecto sobre un paciente, la solución preferente es la pronominalización con un acusativo (Juan la preocupa); por el contrario, cuando el sujeto actúa como la causa del estado psicológico expresado por el verbo, especialmente si el sujeto va pospuesto, entonces se usa el dativo (Le preocupa tu situación). Pero, como se indica en la NGLE (I, 1222-1223), «en gran parte del español americano se acepta también el acusativo aun cuando la situación corresponda a las características que se acaban de describir».

La alternancia acusativo / dativo también aparece en catalán. Pero la variación no se debe a una conversión de todo acusativo en un dativo, caso del leísmo español, sino más bien a razones etimológicas (ej.: ajudar, servir) o a razones de reinterpretación sintáctica como consecuencia de la supresión del complemento directo (acusativo + dativo $>\varnothing+$ dativo $>$ acusativo), que puede afectar a algunos verbos (ej.: robar, ensenyar, pagar, pregar, suplicar). En todos estos verbos hay una tendencia conservadora a mantener el dativo en la zona valenciana y de las Islas Baleares, y una tendencia innovadora, de uso del acusativo, en Cataluña (Ramos, 2005, Morant, 2008). A pesar de eso, la única información normativa, obtenida a través de las entradas del Diccionari de la Llengua Catalana del IEC, da como solución única el acusativo (y en el caso de robar, también el dativo). En cambio, en verbos como contestar, escriure, pegar o telefonar (también trucar) con funcionamiento sintáctico parecido y con una distribución dialectal idéntica, la solución del diccionario es con dativo. Por lo tanto, se produce una falta de homogeneidad en la solución, lo cual se evitaría con un polimorfismo (aceptación de dativo y acusativo) ${ }^{24}$. También resultan problemáticos desde un punto de vista de la norma los usos con los verbos interessar, molestar, preocupar, encantar, impressionar, fascinar, afectar y similares, que, aunque algunos de ellos presenten una solución sintáctica similar a la española, caso de interessar (con sujeto agente: acusativo; con sujeto no agente: dativo), otros presentan soluciones en el diccionario únicamente en acusativo, no siempre coincidentes con gran parte de los hablantes (preocupar, molestar, encantar) (Ramos, 2004; Cabré y Mateu, 1998).

Las combinaciones pronominales son otro ejemplo de variación sintáctica. En español, el caso más significativo es cuando se combinan un complemento directo con referente singular y un complemento indirecto con referente plural: Se lo digo. En estos casos, la solución mayoritaria en América y en Canarias es trasladar la marca de plural al CD, ya que no se puede visualizar en el dativo invariable se: Se los digo. A pesar de la extensión, el carácter normativo de esta segunda solución no tiene un reconocimiento homogéneo, ya que, según la NGLE (II, 2663-2664),

Mientras que en algunas áreas lingüísticas se extiende progresivamente esta construcción a los registros cultos (México, el Caribe continental y parte de las áreas centroamericana, rioplatense y andina), en otras (Chile, España y parte de las áreas andina y antillana) no se considera propia de estos registros.

${ }^{24}$ Aunque el norma española es más tolerante en las alternancias acusativo / dativo, en este tipo de construcciones también manifiesta falta de homogeneidad. Véase la nota anterior.

NORMAS. REVISTA DE ESTUDIOS LINGÜÍSTICOS HISPÁNICOS, NÚMERO 3 (AÑO 2013):

http://www.uv.es/normas

(ISSN 2174-7245) 
Además, cabe consignar la falta de precisión en el uso de expresiones como «parte de las áreas centroamericana, rioplatense y andina»o «parte de las áreas andina y antillana».

El catalán también ha consolidado el polimorfismo normativo en las combinaciones pronominales atendiendo a la variación dialectal (GLC: 135; GNV: 177; Ginebra y Solà, 2007: 177). Se produce concretamente en la combinación de los pronombres átonos de tercera persona en función de complemento directo (singular o plural) y de indirecto (singular): mientras el área valenciana adopta la solución CI + CD, el resto del catalán usa $\mathrm{CD}+\mathrm{CI}$. Además la forma del dativo, en este tipo de combinaciones, también se manifiesta diferente, ya que el valenciano mantiene la forma más habitual, $l i$, y el resto, a causa de una disimilación, la modifica por hi: El regal a Joan, ja li l'he donat / El regal a Joan, ja l'hi he donat.

Los usos preposicionales no están tampoco exentos de variación dialectal. Para el español, este es el caso, por ejemplo, de la preposición hasta y de los usos preposicionales de los adverbios de lugar. La utilización de la preposición hasta en contextos negativos sin la negación explícita (Cerraremos hasta la ocho < No cerraremos hasta las ocho), que se extiende por México, Centroamérica, Colombia, Ecuador y Bolivia, origina un sentido muy diferente al habitual: 'a partir de'. No obstante, con este nuevo sentido tiene una valoración normativa ambigua, tal y como ilustra la cita siguiente:

La negación encubierta es muy común en la lengua conversacional de las áreas mencionadas. En los registros formales es más frecuente incluir la negación en posición preverbal (No cerramos hasta las nueve de la noche) o sustituir la preposición hasta por a si se prefiere mantener el verbo en forma afirmativa (Cerramos a las nueve de la noche), en particular cuando la otra opción podría dar lugar a una situación de ambigüedad entre dos sentidos opuestos (NGLE: II, 3705).

Cabe señalar que unos años antes el $D P D$ (336) no decía «es más frecuente», sino «se recomienda acomodar los usos de hasta en estas zonas al del español general». Este cambio de redacción es el que suponemos que ha hecho calificar como correcto a Gómez Torrego (2011: 170) este uso en las áreas geográficas mencionadas, aunque entendemos que la redacción de la NGLE continúa siendo ambigua.

Más claro es el tratamiento normativo de adverbios como adelante, atrás, arriba, adentro, afuera o abajo en su uso preposicional: abajo de la mesa, arriba de la escalera, atrás de la columna, etc. Este uso, frecuente en América, es aceptado en esta área, pero se rechaza en el español europeo (NGLE: II, 2308).

En catalán, los usos sintácticos de algunas preposiciones también manifiestan variación dialectal. Podemos mencionar, en primer lugar, un ejemplo que, aunque en teoría no tiene opción polimórfica en la norma oficial del IEC, en la práctica la lengua escrita pone de manifiesto este polimorfismo, a menudo consentido o propugnado por la reivindicación de filólogos de prestigio, los medios de comunicación, las editoriales o determinadas entidades. Se trata de la distinción de las preposiciones per y per $a$, que ha quedado neutralizada en la lengua hablada del catalán oriental, y se mantiene en gran parte del catalán occidental. El fenómeno afecta, en el registro coloquial, tanto a los 
usos de las preposiciones seguidos por un sintagma nominal (Treballa per tu /per a tu // Treballa per tu), como a los casos en que preceden a un infinitivo (Treballa per a guanyar diners / Treballa per guanyar diners // Treballa per guanyar diners). Ahora bien, la norma oficial (Fabra, 1933 [1918]: § 128) propugna esta distinción en los usos seguidos de sintagma nominal, lo cual facilita la distinción causa / destino, pero aplica, en los casos seguidos de infinitivo, una norma que no se corresponde con el uso de ninguna de las zonas dialectales y cuya aplicación requiere antes una reflexión por parte del usuario. Ante esta falta de correspondencia y ante las dificultades de aplicación, han surgido propuestas alternativas más acordes con la variación dialectal, como el uso exclusivo de la preposición per o la posibilidad de que ante infinitivos también se pueda aplicar la distinción per/per $a^{25}$. Esta última posibilidad es la que, aunque en convivencia con la norma ortodoxa, también se propone desde la Acadèmia Valenciana de la Llengua (GNV: 204-205).

Otro ejemplo preposicional de interés son los usos de en y a ante locativos en catalán. A grandes rasgos, la propuesta normativa (Fabra, 1933 [1918]: § 125) suele coincidir con la mayoría de los dialectos. Pero, en los usos de estas preposiciones delante de topónimos o de localizaciones físicas precedidas de artículo definido, en los que la preposición $a$ es la adoptada por la norma, buena parte del área dialectal valenciana prefiere la solución con la preposición en (Viu a/en València; L'he vist al/en el carrer). Esta circunstancia ha provocado que la GNV (199-200), a pesar de su convergencia básica con la norma del IEC, propugne un polimorfismo a/en en las localizaciones físicas precedidas de artículo definido ( $L$ 'he vist al/en el carrer), sin apartarse de la norma general en los topónimos (Viu a València).

\section{CRITERIOS DE APLICACIÓN DEL POLIMORFISMO}

El polimorfismo descrito en el apartado anterior surge para satisfacer la identificación del usuario, procedente de áreas geográficas diferentes, con la norma. Pero el hecho de que se permita un mayor o un menor polimorfismo está conectado con la manera como se ha concebido históricamente la norma.

Recordemos que, en el caso del español, tenía una base unitarista, sobre el modelo de la zona central y septentrional de España, y en el caso del catalán, composicional, con aportaciones más o menos establecidas de diferentes dialectos, pero también con un peso específico del catalán central (cf. § 4.1). Este origen diferente no es ninguna banalidad, ya que de alguna manera también condiciona la redacción de la norma y de su variación polimórfica: la solución no marcada o primera suele ser la que se identifica como referente, la de España en el español y la de Cataluña en catalán, y la marcada o segunda es la que abre la puerta a la otra opción, la «dialectal». Por ejemplo, en el caso del español, el modelo regular de la conjugación verbal de amar en la segunda persona del presente de indicativo se representa así (NGLE: I, 254): Tú/vós amas/amás. Lo

\footnotetext{
${ }^{25}$ Para un seguimiento de la polémica, se puede consultar Sancho (2002: $\left.§ ~ 11.5 .4 .3\right)$.
} 
mismo ocurre, en el caso del catalán, a la hora de ilustrar la primera persona del presente de indicativo del verbo cantar (GLC: 202): canto (cante, cant).

Es evidente que se podría argumentar que las primeras son mucho más habituales que las segundas, con más implantación en los textos escritos y más prestigiosas actualmente. Pero todas estas razones de alguna manera también están condicionadas y determinadas por la concepción inicial de la norma. Por otro lado, no se debe perder de vista dónde se publica o de dónde procede el tratado gramatical: en el caso del español, de Madrid; en el caso del catalán, de Barcelona. Ni tampoco qué modelo de lengua se quiere proyectar hacia el interior y hacia el exterior, entiéndase el uso de la lengua en países o comunidades del mismo idioma o de diferente, o la enseñanza de la lengua como lengua 1 (L1) o como lengua 2 (L2) ${ }^{26}$. Por lo tanto, la redacción no es azarosa, sino que tiene una ideología lingüística subyacente ${ }^{27}$.

También es importante conocer los criterios que guían las alternativas normativas. Tanto las obras académicas del español como las del catalán suelen coincidir en los criterios siguientes, que no son independientes, sino que de alguna manera interactúan: a) la extensión del fenómeno en diferentes áreas dialectales o países (o comunidades autónomas); b) la tradición escrita culta: consolidación y implantación en la zona geográfica; c) el prestigio entre la gente de cultura; d) el hecho de ser una característica documentada en la lengua antigua; y e) el grado de implantación en la lengua oral estándar (medios de comunicación). Asimismo, en general se suele rechazar sistemáticamente cualquier indicio de que la solución pueda ser una interferencia de otra lengua. Por ejemplo, en el caso del español se tiene un cuidado especial en el contacto con las lenguas amerindias, el inglés y el catalán; en el caso del catalán, en la interferencia procedente del español.

Aunque la aplicación de estos criterios haya guiado las posibles alternativas normativas, se hace necesaria otra reflexión: ¿este polimorfismo sirve para cualquier situación o está restringido al territorio en el que aparecen estas formas? La respuesta es evidente a la luz de la presentación de la variación en los tratados gramaticales académicos: las alternativas son válidas en los territorios donde son habituales, y no en las zonas que no lo son. Este hecho comporta que la elección de las opciones lingüísticas tiene que ser homogénea dentro de un territorio geográfico, de manera que un mismo texto escrito no puede contener soluciones características de zonas diferentes. Partiendo de este criterio, por ejemplo, en el español de España resultaría inadecuada la asignación de una forma de plural al acusativo para marcar el dativo plural en expresiones como Se los digo; en el catalán de la Comunidad Valenciana, también se consideraría inadecuado el uso de la combinación pronominal CD+ CI, l'hi, con este orden y con la forma de dativo hi. No es raro, pues, que, tanto en español como en catalán, los tratados gramaticales describan la variación de la norma en términos restrictivos y se considere una falta de adecuación dicha mezcla.

\footnotetext{
${ }^{26}$ Para una reflexión sobre el papel de la variación en la enseñanza del español como L2, véase Martín Zorraquino (2002) y Andión (2007, 2008).

${ }^{27}$ En el caso del catalán, esta ideología, por contraste con la $G L C$, aún es más evidente en la redacción y en las propuestas de la $G N V$.
} 
Ahora bien, esta restricción, en la práctica, no se suele establecer atendiendo a la amplitud geográfica de una solución lingüística, sino a los límites políticos donde predomina esta solución. Por tanto, nos podemos encontrar con otro problema: ¿qué pasa cuando las soluciones linguiísticas no abrazan toda la extensión política o la sobrepasan? En general, los tratados gramaticales dan preferencia a las soluciones mayoritarias de cada zona política y marginan las soluciones minoritarias. Esta marginación se puede realizar de dos formas: en términos positivos, apuntándose como una observación, o en términos negativos, aludiendo a la falta de prestigio en los registros cultos de una determinada zona. La primera manera de proceder es la habitual en las gramáticas del ámbito catalán. La segunda suele ser frecuente en las obras académicas del español.

Veamos un ejemplo que conecta con el citado anteriormente: en la parte más septentrional de la Comunidad Valenciana, también se utiliza la solución l'hi, propia del modelo de Cataluña; en cambio, no forma parte del modelo propuesto para esta comunidad, y se alude a esta solución a modo de observación puntual sin que haya proscripción normativa $(G N V$ : 177). Dentro de España, Canarias también utiliza la construcción Se los digo, pero la NGLE (II: 2663) rechaza su uso en territorio español, y lo aprueba, como hemos advertido más arriba, en países de América. En este sentido, llama especialmente la atención que, a pesar de la intencionalidad panhispánica manifestada en el ideario de esta obra, todavía el peso del modelo tradicional unitarista sea una losa que, por un lado, impide a las zonas dialectales de España mostrar su variación cuando ya es una norma aceptada en América ${ }^{28}$; y por otro, que dentro de los países americanos, en unos el fenómeno en cuestión adquiera ya el estatus de normativo y en otros continúe soportando el estigma de solución divergente del modelo unitarista español y, por lo tanto, se perciba como no normativo ${ }^{29}$.

\section{EL POLIMORFISMO COMO PUNTO DE PARTIDA DE UN MODELO NORMATIVO NACIONAL O REGIONAL}

Otro aspecto digno de comentario es hasta qué punto el polimorfismo es capaz de proyectar y de generar un modelo normativo con el cual se pueda sentir identificado un territorio político. O lo que es lo mismo, ¿las obras académicas del español y del catalán permiten extraer modelos estándar para los diferentes países de habla hispana o para las comunidades autónomas de habla catalana, respectivamente?

En catalán, la situación sociolingüística, la codificación gramatical inicialmente composicional y la reivindicación identitaria de las comunidades de habla catalana han provocado que la lengua escrita ya tenga una larga tradición en la aplicación del

${ }^{28}$ Nótese que el criterio adoptado en España de rechazar la construcción Se los digo en los registros formales, no es homogéneo con la aceptación en Canarias (y en Andalucía occidental) de otro fenómeno compartido con América: la convergencia de ustedes con vosotros (DPD: 659; NGLE: I, 192193).

${ }^{29}$ Recuérdese que en Chile y en parte de las áreas andina y antillana, según la NGLE (II: 2663), no es una construcción propia de los registros cultos. 
polimorfismo. Por lo tanto, las gramáticas académicas ( GLC y $G N V)$ recogen estos usos regionales, y los tratados gramaticales no académicos y los manuales escolares de los diferentes territorios aplican sus respectivos modelos estándar. Este hecho es una realidad en las comunidades autónomas de las Islas Baleares, la Comunidad Valenciana y Cataluña. Ahora bien, también cabe destacar que dentro de Cataluña el modelo escrito del catalán central, con el foco irradiador de Barcelona, se impone sobre la variación polimórfica oral, próxima en algunos aspectos al valenciano, que podría manifestar en los textos escritos la zona del catalán noroccidental ${ }^{30}$. También tiene como base este modelo Andorra y, en la medida de sus posibilidades sociolingüísticas, la zona aragonesa y francesa de habla catalana. En el caso de la ciudad de Alguer (Cerdeña), llama especialmente la atención que el IEC (IEC, 2003), dada la especial situación sociolingüística de esta variante dialectal, elaboró un modelo normativo divergente del resto del catalán (Segarra, 2006).

En el caso del español, se hace realmente difícil, a través de la consulta de la $N G L E$, establecer modelos estándar aplicables a territorios o países diferentes, lo que se ha venido en llamar las normas nacionales o regionales. Aunque el mismo ideario de la NGLE (I, XLII) reconoce implícitamente estos modelos y los presenta, en principio, en plan de igualdad, aludiendo al policentrismo y al hecho de que «no es posible presentar el español de un país o de una comunidad como modelo panhispánico de lengua», la realidad es que cualquier intento de extraer modelos homogéneos aplicables a países diferentes de España, como, por ejemplo, los americanos, choca con toda una serie de dificultades $^{31}$. Hemos aludido más arriba a la falta de precisión que a menudo se observa en la identificación de los países o zonas donde se da el fenómeno aceptado como norma. La misma NGLE (I, XLIV) ya advierte que

no debe esperarse el grado de detalle que correspondería a un tratado de dialectología. Las referencias específicas se introducen muchas veces en función de países o de regiones, pero en la mayor parte de los casos se establecen a partir de zonas o áreas lingüísticas más amplias. Son las que están representadas en la Comisión Interacadémica de la Nueva gramática que coordinó los trabajos, las mismas que se establecieron para el Diccionario panhispánico de dudas: Chile, Río de la Plata, área andina, Caribe continental, México y Centroamérica, Antillas, Estados Unidos y Filipinas, y España.

Pero el lector hubiera agradecido que, como mínimo, los fenómenos admitidos por la norma estuvieran bien delimitados geográficamente. Son demasiado habituales expresiones como «en parte de», «en muchos países de», «en algunos países de», «en casi toda», «en buena parte de», «en otras áreas de», «en ciertas zonas de», «y también

\footnotetext{
${ }^{30}$ Sobre la nivelación dialectal que está sufriendo esta zona noroccidental del catalán a favor de las soluciones del catalán central, véase Massanell (2012). Esta autora también hace una interesante reflexión cuando pone de manifiesto que la división administrativa autonómica entre Cataluña, Baleares y la Comunidad Valenciana, con un modelo estándar de referencia para cada una, va en detrimento de un posible modelo pancatalán, y contribuye a que la fronteras dialectales tiendan cada vez más a coincidir con los límites administrativos (Massanell, 2012: 195).

${ }^{31} \mathrm{Ni}$ que decir tiene en el caso de países de habla hispana no americanos, de los cuales la información gramatical es inexistente.
} 
en..., entre otras», etc. También es ambigua la referencia al Caribe, ya que, junto con el adjetivo continental, se identifica con Colombia y Venezuela, pero sin él parece incluir también el área de las Antillas. Esta manera de redactar, con imprecisiones o referencias dispersas, conduce más fácilmente a la identificación de un gran modelo estándar americano, a pesar de las indudables diferencias dialectales dentro de América, que no a modelos nacionales. De hecho, estos posibles modelos nacionales escritos, en el caso de que finalmente el lector pueda percibirlos, acaban poniéndose más de manifiesto por determinadas divergencias particulares que por un conjunto sistemático de soluciones alternativas.

Por ejemplo, de acuerdo con la información de la NGLE, podemos deducir, a grandes rasgos, un modelo normativo americano que contraste con el de España: la variación del género de algunos nombres, ausencia del leísmo aceptado, los regímenes verbales (acusativo/dativo; de carácter preposicional), sistema binario de deícticos, ausencia de vosotros y de vuestro, tendencia a la neutralización canté/he cantado, preferencia por los usos verbales perifrásticos, deber + infinitivo (valor de probabilidad), estar + bueno (con adjetivos que indican característica), usos preposicionales de adelante, atrás, arriba + de, capaz ('quizá'), anteposición de nunca ante un verbo en infinitivo (Van a desear ustedes nunca haberlo hecho), conectores como mientras que (valor temporal) o no más, y estructuras enfáticas del tipo ¿Cómo fue que ocurrió?.

Pero, si queremos ir más allá, y lo que deseamos es intentar extraer un modelo aplicable a un país concreto, hay países con una descripción, o lo que es lo mismo, con una aceptación de la variación más generosa que otros, seguramente como consecuencia de su peso dentro del ámbito hispánico. Se benefician de esta concesión, sobre todo el área del Río de la Plata y de México. Por ejemplo, en este último caso, al modelo americano anterior deberíamos añadir: la discordancia en construcciones del tipo Habría que irnos, el uso enfático de le, presencia del leísmo en las impersonales, posibilidad de combinar el artículo indefinido con un posesivo (un su grupo), uso del cuantificador harto, uso del verbo saber + interrogativa indirecta en subjuntivo, al + infinitivo con valor condicional, la concordancia del dativo sobre el acusativo (Se los digo), entre en las comparativas proposicionales ('cuanto, mientras'), y, si es su caso, la preposición hasta con valor de 'a partir de'. En cuanto a los países del Río de la Plata (la Argentina, Paraguay y Uruguay), la característica principal es el voseo pronominal y el verbal, también admite la concordancia del dativo sobre el acusativo ( $\mathrm{Se}$ los digo) o el uso de conectores como todavía que con valor concesivo y desde que con valor causal.

Respecto a las otras áreas o países americanos, la $N G L E$ se muestra mucho más restrictiva y dispersa en relación con la aceptación de la variación dialectal: se suelen aceptar los fenómenos antes mencionados coincidentes con el área mexicana y la rioplatense, aunque no siempre (véase el caso del voseo más arriba $\S 4.2 .2 .1 \mathrm{o}$ el de la concordancia en Se los digo, § 4.1.3). No obstante, se consideran como no propios del registro culto otros muchos usos, a pesar también de que algunos de ellos sean incluso compartidos por estas áreas: medio concordado, posesivo duplicado, anteposición del sujeto al infinitivo, decir para + infinitivo (= decir que), deber de + infinitivo (valor de 
obligación), ir + gerundio ('inminencia'), anteposición del sujeto en las interrogativas, anteposición de más (lo más que me gusta, más nunca), entre otros.

\section{SOBRE LA VALIDEZ DE LOS MODELOS NACIONALES O REGIONALES EN OTROS ENTORNOS}

Hemos visto, pues, que, a pesar de las dificultades apuntadas sobre todo en el caso del español, es posible establecer normas o modelos nacionales o regionales. Pero, si de acuerdo con el ideario de los obras académicas actuales, en teoría todos los modelos tienen la misma importancia, y todos contribuyen a la unidad de la lengua en la diversidad, ahora la pregunta que deberíamos hacernos es: ¿cualquiera de estos modelos, y siempre que se aplique de manera homogénea, se debería aceptar fuera de su entorno geográfico? Es decir, un autor originario de otra zona geográfica puede mantener su modelo escrito en otra zona geográfica de su misma lengua.

La respuesta debería ser sí, ya que esto contribuiría a un mayor conocimiento de la lengua y a una mayor integración ${ }^{32}$. Esto supondría, por ejemplo, que un autor argentino podría colaborar en un diario de España utilizando su modelo estándar, o que un autor valenciano podría hacer lo mismo en un diario catalán. Esta manera de actuar se hace cada vez más visible en los modelos orales por medio de los productos audiovisuales (televisión y cine). Pero en el ámbito de la escritura queda mucho camino por trazar.

Por ejemplo, en catalán, que cuenta con una tradición de décadas en la aplicación de modelos geográficos, aunque lo más habitual es respetar el modelo de procedencia del autor, no siempre es posible. Las razones que se aducen para evitar esta convivencia suelen girar alrededor del mercado o de la identificación con el destinatario más próximo. Pero, detrás de esta decisión, muchas veces hay un componente ideológico de no asunción de todos los modelos como equivalentes. Desde Cataluña, no es extraño considerar como «dialectal» el modelo valenciano y el balear ${ }^{33}$; desde la Comunidad Valenciana y las Islas Baleares, se organizan a menudo campañas planificadas, sobre todo desde los sectores políticos más conservadores y españolistas, de desprestigio del modelo de Cataluña calificándolo de invasor de su territorio.

En el caso del español, la nueva política panhispanista habrá que ver hasta qué punto es tolerante con la posibilidad de utilizar diversos modelos en un mismo territorio. Por ahora, el predominio del modelo de España era completamente asumido en América. Pero, ¿el modelo o los modelos escritos procedentes de América, exención hecha del ámbito literario, pueden llegar a tener también buena acogida en España? Es todavía demasiado pronto para saber qué puede pasar en un país tan acostumbrado al modelo único. De momento, ya han surgido voces críticas, tanto en España como en

\footnotetext{
${ }^{32}$ Pensamos que la línea argumentativa policéntrica de Rivarola (2001) iba en este sentido.

${ }^{33}$ Sobre este punto, llama especialmente la atención que, a pesar de la permisividad polimórfica, más allá de la norma estrictamente académica, mostrada en la redacción de la prestigiosa Gramàtica del Català Contemporani en aspectos sintácticos, e incluso ortográficos (signos de interrogación y de admiración al principio y al final frente a la norma oficial que solo los permite al final) (cf. Solà, 2004), en el plano morfológico únicamente se aceptaron las formas propias del modelo de Cataluña.
} 
América, que ponen en cuestión la nueva política panhispanista de la RAE y la Asociación de Academias de la Lengua Española. Las críticas no son por potenciar el polimorfismo y, por lo tanto, los modelos geográficos, en lo cual están completamente de acuerdo, sino por hacerlo, por un lado, por intereses mercantilistas: vender la Marca España en América; y por otro, porque esta política panhispanista pierde credibilidad si al mismo tiempo la RAE da cobertura en América a proyectos linguísticos uniformadores como la Fundéu (Fundación del Español Urgente) ${ }^{34}$.

\section{CONCLUSIONES}

A lo largo de este artículo hemos podido observar que tanto el español como el catalán tienen en cuenta alternativas formales de origen geográfico en sus propuestas de la norma escrita. Ahora bien, a pesar de que la extensión dialectal del español es muy superior a la del catalán, sus circunstancias sociolingüísticas distintas y la concepción diferente de la norma en su génesis (unitarista, en el primer caso, y composicional, en el segundo) han originado que el catalán sea bastante más permisivo en el polimorfismo que el español.

Las dos lenguas muestran pocas alternativas en el plano ortográfico, pero son más generosas en los planos sintáctico y morfológico. En este último plano, llama especialmente la atención, por la variedad de soluciones, la norma catalana.

La aplicación homogénea de estas opciones permite (o podrá permitir) la creación de modelos estándar identificables con determinadas zonas geográficas (modelos nacionales, regionales o autonómicos). Estos modelos, en teoría, de acuerdo con el ideario de las gramáticas académicas, deberían tratarse en pie de igualdad. Pero hemos señalado que la validez de estos modelos fuera de su ámbito geográfico, más en el caso del español que en el del catalán, choca a menudo con prejuicios lingüísticos o con un interés mercantilista que favorece más la tendencia uniformadora que la polimórfica. Asimismo, intereses políticos pueden potenciar la tendencia polimórfica sobre la uniformadora, como es el caso de la $G N V$ en catalán.

Por otro lado, tanto en español como en catalán, a pesar de que sus obras académicas tienen presente el polimorfismo, la presentación de los contenidos evita seguir esquemas claros de diferenciación de modelos estándar nacionales o regionales. A pesar de eso, el lector puede construir estos modelos con más facilidad en el caso del catalán que en el del español, ya que la redacción de las opciones normativas suele ser más sistemática y, desde un punto de vista territorial, más precisa.

${ }^{34}$ Véase sobre todo el trabajo de Lara (2011) y Senz (2011), pero también muchos de los estudios que contiene la obra coordinada por Senz y Alberte (2011), especialmente críticos con la utilización de la lengua como pretexto para abrirse mercados internacionales.

NORMAS. REVISTA DE ESTUDIOS LINGÜISTICOS HISPÁNICOS, NÚMERO 3 (AÑO 2013):

http://www.uv.es/normas

(ISSN 2174-7245) 


\section{REFERENCIAS BIBLIOGRÁFICAS}

Acadèmia Valenciana de la Llengua (AVL) (2002): De les normes de Castelló a l'Acadèmia Valenciana de la Llengua, València, AVL.

ACADÈMIA VALENCIANA DE LA LlenguA (AVL) (2006): Gramàtica normativa valenciana $(G N V)$, València, Publicacions de l'AVL [en línea]: <http://www.avl.gva.es/va/documents-normatius/.../GNV.pdf>. [Consulta: 03-06-2013].

ALEZA IZQUIERDO, Milagros (2006a): «Lengua estándar y variedades de la lengua española», en Aleza, Milagros, coord., Lengua española para los medios de comunicación: usos y normas actuales, Valencia, Tirant lo Blanch, 27-45.

AlEZA IZQUIERDO, Milagros (2006b): «Cuestiones gramaticales y desviaciones frecuentes», en Aleza, Milagros, coord., Lengua española para los medios de comunicación: usos y normas actuales, Valencia, Tirant lo Blanch, 47-101.

AlEZA IZQuIERDO, Milagros (2010): «Morfología y sintaxis. Observaciones gramaticales de interès en el espanyol de América», en Aleza, Milagros y José M. Enguita, coords., La lengua española en América: normas y usos actuales, Valencia, Universitat de València, 95-223 [en línea]: 〈http://www.uv.es/aleza/esp.am.pdf〉.

ALEZA IZQUIERDO, Milagros (2011a): «La unidad de la lengua en la pluralidad de normas», en Aleza, Milagros, coord., Normas y usos correctos en el español actual, Valencia, Tirant Humanidades (edición corregida y actualizada), 57-74.

AlEZA IZQUIERDO, Milagros (2011b): «Normas, usos gramaticales y errores frecuentes», en Aleza, Milagros, coord., Normas y usos correctos en el español actual, Valencia, Tirant Humanidades (edición corregida y actualizada), pp. 77-117.

Aleza IzQUiERdo, Milagros y José M. EnguiTa UtriLla (2010): «Introducción», en Aleza, Milagros y José M. Enguita, coords., La lengua española en América: normas $y$ usos actuales, Valencia, Universitat de València, 23-49 [en línea]: <http://www.uv.es/aleza/esp.am.pdf>.

Alomar, Antoni I. (2006): «La codificació de la llengua catalana a les Illes Balears al segle XX», en Ferrando, Antoni y Miquel Nicolás, eds., La configuración social de la norma lingüistica a l'Europa llatina, Alacant, Institut Interuniversitari de Filologia Valenciana, 267-298.

ANDIÓN, M. Antonieta (2007): «Las variedades y su complejidad conceptual en el diseño de un modelo lingüístico para el español L2/LE», ELUA. Estudios de Lingüística Universidad de Alicante, 21, 21-33.

ANDIÓN, M. Antonieta (2008): «Modelo, estándar y norma..., conceptos imprescindibles en el español L2/LE», Revista Española de Lingüística Aplicada, 21, 926.

BARRIOS, Graciela (2011): «La regulación política de la diversidad: academias de lenguas y prescripción idiomática», en Senz, Silvia y Montserrat Alberte, eds., El dardo en la Academia. Esencia y vigencia de las academias de la lengua española, vol. 1, Barcelona, Melusina, 591-619.

Bentivoglio, Paola (2001): «La variación sociosintáctica en español», en II Congreso Internacional de la Lengua Española. El español en la sociedad de la información, Madrid, Instituto Cervantes [en línea]: <http://congresosdelalengua.es/ 
valladolid/ponencias/unidad_diversidad_del_espanol/1_la_norma_hispanica/bentivoglio _p.htm>. [Consulta: 22-02-2013].

BIBILONI, Gabriel (2004): Llengua estàndard $i$ variació lingüística, València, Tres i Quatre.

BlECUA, J. Manuel (2001): «Unidad, variedad y enseñanza», en II Congreso Internacional de la Lengua Española. El español en la sociedad de la información, Madrid, Instituto Cervantes [en línea]: <http://congresosdelalengua.es/valladolid/ ponencias/unidad_diversidad_del_espanol/1_la_norma_hispanica/blecua_j.htm>.

[Consulta: 22-02-2013].

CABRÉ, Teresa y Jaume MATEU (1998): «Estructura gramatical i normativa: a propòsit dels verbs psicològics en català», Quaderns. Revista de traducció, 2, 65-81.

CARTAGENA, Nelson (2001): «Conservación y variación como factores de divergencia del verbo español en América. Posibilidades y límites de convergencias normativas», en II Congreso Internacional de la Lengua Española. El español en la sociedad de la información, Madrid, Instituto Cervantes [en línea]: $<$ http://congresosdelalengua.es/valladolid/ponencias/unidad_diversidad_del_espanol/2_ el_espanol_de_america/cartagena_n.htm>. [Consulta: 22-02-2013].

DEMONTE, Violeta (2001): «El españo estándard (ab)suelto. Algunos ejemplos del léxico y la gramática». en II Congreso Internacional de la Lengua Española. El español en la sociedad de la información, Madrid, Instituto Cervantes [en línea]: <http://congresosdelalengua.es/valladolid/ponencias/unidad_diversidad_del_espanol/1_1 a_norma_hispanica/demonte_v.htm>. [Consulta: 22-02-2013].

DEMONTE, Violeta (2004): «La esquiva norma del español. Sus fusiones y relaciones con la variación y el estándar», en Álvarez, Rosario y Henrique Monteagudo, eds., Norma lingüística e variación. Unha perspectiva desde o idioma galego, Santiago de Compostela, Consello da Cultura Galega/Instituto da Lingua Galega, 13-29.

DíAZ SALGADO, Luis Carlos (2011): «Historia crítica y rosa de la Real Academia Española», en Senz, Silvia y Montserrat Alberte, eds., El dardo en la Academia. Esencia y vigencia de las academias de la lengua española, vol. 1, Barcelona, Melusina, 21-156.

FABRA, Pompeu (1933 [1918]): Gramàtica catalana, Barcelona, IEC (7.a edición. Reimpresión en: Solà, Joan y Jordi Mir dir. (2009): Pompeu Fabra. Obres completes, vol. 6, Barcelona, Proa/Edicions 62/Tres i Quatre/Moll.

FAJARDO, Alejandro (2011): «La norma lingüística del español desde una perspectiva lexicográfica: norma nacional versus norma panhispánica», Normas. Revista de estudios lingüísticos hispánicos, 1, 53-70 [en línea]: <http://www.uv.es/normas/normas_2011.html>. [Consulta: 22-03-2013].

FERRANDO, Antoni (2006): «Percepció i institucionalització de la norma lingüística entre els valencians: panorama històric», en Ferrando, Antoni y Miquel Nicolás, eds., La configuración social de la norma lingüística a l'Europa llatina, Alacant, Institut Interuniversitari de Filologia Valenciana, 189-251.

GineBRA, Jordi y Joan SolÀ (2007): Pompeu Fabra: vida i obra, Barcelona, Teide. 
Gómez Molina, José Ramón (2011): «La preposición 'de' como mecanismo comunicativo en las construcciones ' $\varnothing / \mathrm{de}+$ que + verbo en forma personal'», Oralia 14 , 345-376.

Gómez Molina, José Ramón (en prensa): «Pluralización de haber impersonal en el español de Valencia (España)», Verba 40.

GÓMEZ TORREGO, Leonardo (2011): Las normas académicas: últimos cambios, Madrid, Ediciones SM.

GregOry, Michael y Susanne CARroll (1978): Language and situation, Londres, RKP.

InSTITUT D'EstUdis CATALANS (IEC) (1999): Proposta per a un estàndard oral de la llengua catalana. 2, Morfologia, Barcelona, $\mathbb{E C}$ [en línea]: $<$ http://www.iecat.net/institucio/seccions/Filologica/pdf/Proposta\%20estndard\%202.pdf>. [Consulta: 12-06-2013].

InSTITUT D'ESTUDIS CATALANS (IEC) (2003): Model d'àmbit restringit de l'alguerès [en línea]: <http://www.iecat.net/institucio/seccions/Filologica/pdf/CatalaALGUER.pdf)>. [Consulta: 03-06-2013].

InstiTUT D'EstUdis CATALANS (IEC) (2007): Diccionari de la Llengua Catalana, Barcelona, IEC [en línea]: <http://dlc.iec.cat/>. [Consulta: 15-06-2013].

INSTITUT D'ESTUDIS CATALANS (IEC): Gramàtica de la Llengua Catalana $(G L C)$, esbozo provisional [en línea]: <http://www.iecat.net/institucio/seccions/filologica/gramatica/>. [Consulta: 04/06/2013].

LARA, Luis Fernando (2011): «El símbolo, el poder y la lengua», en Senz, Silvia y Montserrat Alberte (eds.) El dardo en la Academia. Esencia y vigencia de las academias de la lengua española, vol. 1, Barcelona, Melusina, 315-341.

LLITERAS, Margarita (2006): «La configuración histórica de la norma española», en Ferrando, Antoni y Miquel Nicolás, eds., La configuración social de la norma lingüística a l'Europa llatina, Alacant, IIFV, 55-75.

LOPE BLANCH, Juan Miguel (2001): «La norma y las normas. El español estándar» en II Congreso Internacional de la Lengua Española. El español en la sociedad de la información, Madrid, Instituto Cervantes [en línea]: <http://congresosdelalengua. es/valladolid/ponencias/unidad_diversidad_del_espanol/1_la_norma_hispanica/lope_j.h tm>. [Consulta: 15-02-2013].

LÓPEZ GARCíA, María (2010) «Norma estándar, variedad lingüística y español transnacional: ¿La lengua materna es la lengua de la "madre patria"? », Revista de Lingüística y Lenguas Aplicadas, 8, 89-108.

MARÍ, Isidor (1987): "Varietats i registres en la llengua dels mitjans de comunicación de masses», en Cabré, Maria Teresa et alii, eds., Actes de les segones jornades d'estudi de la llengua normativa, Barcelona, PAM, 9-30.

MARTín ZoRRAQUiNO, M. Antonia (2002) «Norma y variación linguiísticas en la enseñanza de E/ELE», en Martín Zorraquino, M. Antonia, coord., ¿Qué español enseñar? Norma y variación lingüísticas en la enseñanza del español a extranjeros, Zaragoza, Prensas Universitarias de Zaragoza, 7-11. 
MARTíneZ DE SouSA, José (2011): «La obra académica a lo largo de tres siglos», en Senz, Silvia y Montserrat Alberte, eds., El dardo en la Academia. Esencia y vigencia de las academias de la lengua española, vol. 1, Barcelona, Melusina, 621-689.

MAS, Josep A. (2008): El morfema ideològic. Una anàlisi crítica dels models de llengua valencians, Benicarló, Onada Edicions.

MASSANELL, Mar (2012): «Feve temps que no diva tants verbs!». Manteniment $i$ transformación de paradigmas verbals en el català nord-occidental del tombant de segle, Barcelona, Publicacions de l'Abadia de Montserrat.

MORANT, Marc (2008): L'alternança datiu/acusatiu en la recció verbal catalana, València, Tesis doctoral inédita.

Moreno CABrerA, Juan Carlos (2011) «'Unifica, limpia y fija.’ La RAE y los mitos del nacionalismo lingüístico español», en Senz, Silvia y Montserrat Alberte, eds., El dardo en la Academia. Esencia y vigencia de las academias de la lengua española, vol. 1, Barcelona, Melusina, 157-314.

MORENO FERnÁNDEZ, Francisco (2009): La lengua española en su geografía, Madrid, Arco/Libros.

NADAL, Josep Maria (2006): «La llengua normal», en Ferrando, Antoni y Miquel Nicolás, eds., La configuración social de la norma lingüística a l'Europa llatina, Alacant, IIFV, 15-30.

NARBONA, Antonio (2001): «Movimientos centrífugos y centrípetos en la(s) norma(s) del español», en II Congreso Internacional de la Lengua Española. El español en la sociedad de la información, Madrid, Instituto Cervantes [en línea]: $<$ http://congresosdelalengua.es/valladolid/ponencias/unidad_diversidad_del_espanol/1_1 a_norma_hispanica/narbona_a.htm>. [Consulta: 15-02-2013].

NiCOLÁs, Miquel (2006): «La producció social de la norma linguiística: notes per a un marc teòric», en Ferrando, Antoni y Miquel Nicolás, eds., La configuración social de la norma lingüistica a l'Europa llatina, Alacant, IIFV, 31-51.

PÉREZ SALDANYA, Manuel y Gemma Rigau (2005): «Variació gramatical i prescripció», en Institut d'Estudis Catalans, Jornades de la Secció Filològica de l'Institut d'Estudis Catalans a l'Institut Interuniversitari de Filologia Catalana: 15 i 16 d'octubre de 2004, Barcelona, IEC, 109-124.

PrADILla, Miquel A. (2008): La tribu valenciana. Reflexions sobre la desestructuración de la comunitat lingüística, Benicarló, Onada Edicions.

RAMíREZ GELBES, Silvia (2011): «Correctores, periodistas y la Academia Argentina de Letras: amores y desamores», en Senz, Silvia y Montserrat Alberte, eds., El dardo en la Academia. Esencia y vigencia de las academias de la lengua española, vol. 2, Barcelona, Melusina, 560-578.

RAMíREZ LuENGO, José Luis (2007) «Más allá del océano: una descripción del español en Amèrica», Per Abbat, 2, 73-99 [en línea]: http://dialnet.unirioja.es/servlet/ listaarticulos?tipo_busqueda=EJEMPLAR\&revista_busqueda $=7988 \&$ clave_busqueda $=$ 150014). [Consulta: 20-03-2013].

RAMOS, Joan-Rafael (2001): «El verb haver-hi: evolució dels usos sintàctics», Estudis Romànics, 23, 123-146. 
RAMOS, Joan-Rafael (2002): «El SV, II: la predicación no verbal obligatòria», en Solà, Joan et alii, dir., Gramàtica del català contemporani, vol. 2, Barcelona, Empúries, 1951-2044.

RAMOS, Joan-Rafael (2004): «El règim verbal: anàlisi contrastiva català-castellà», Quaderns de filología. Estudis lingüístics, 9, 119-139.

RAMOS, Joan-Rafael (2005): «El complement indirecte: l'alternança datiu/acusatiu», Estudis Romànics 27, 93-111.

REAl ACADEMIa DE LA LENGUa EsPañola (RAE) y Asociación DE ACADEMIAS DE LA LENGUA EsPaÑola (ASALE) (2005): Diccionario panhispánico de dudas (DPD), Madrid, Santillana.

REAL ACADEMIA DE LA LENGUA ESPAÑola (RAE) y Asociación DE ACADEMIAS DE LA LENGUA ESPAÑOLA (ASALE) (2009): Nueva gramática de la lengua española (NGLE), 2 vols., Madrid, Espasa.

REAl ACADEMIA DE LA LENGUA EsPaÑola (RAE) y Asociación DE ACADEMIAS DE LA LENGUA EsPañola (ASALE) (2010): Ortografía de la lengua española (OLE), Madrid, Espasa.

RICós, Amparo (2011): «El español: origen y situación actual», en Aleza, Milagros, coord., Normas y usos correctos en el español actual, Valencia, Tirant Humanidades (edición corregida y actualizada), 28-55.

Rivarola, José Luis (2001): «Sobre variedades y normas del español en el marco de una cultura lingüística pluricéntrica», en II Congreso Internacional de la Lengua Española. El español en la sociedad de la información, Madrid, Instituto Cervantes: $<$ http://congresosdelalengua.es/valladolid/ponencias/unidad_diversidad_del_espanol/1_1 a_norma_hispanica/rivarola_j.htm>. [Consulta: 15-02-2013].

ROJAS MAYER, Elena (2001) «La norma hispànica: prejuicios y actitudes de los argentinos en el siglo XX», en II Congreso Internacional de la Lengua Española. El español en la sociedad de la información, Madrid, Instituto Cervantes [en línea]: <http://congresosdelalengua.es/valladolid/ponencias/unidad_diversidad_del_espanol/1_1 a_norma_hispanica/rojas_e.htm>. [Consulta: 15-02-2013].

SANCHO, Pelegrí (2002): «La preposición i el sintagma preposicional», en Solà, Joan et alii, dir., Gramàtica del català contemporani, vol. 2, Barcelona, Empúries, 1689-1796.

SEGARRA, Mila (1985): Història de la normativa catalana, Barcelona, Enciclopèdia Catalana.

SEgARRA, Mila (2006): «Tradició i modernitat en la configuració de la norma catalana a Catalunya», en Ferrando, Antoni y Miquel Nicolás, eds., La configuración social de la norma lingüística a l'Europa llatina, Alacant, IIFV, 156-187.

SENZ, Silvia (2011): «Una, grande y (esencialmente) uniforme. La RAE en la conformación y expansión de la "lengua común"», en Senz, Silvia y Montserrat Alberte, eds., El dardo en la Academia. Esencia y vigencia de las academias de la lengua española, vol. 2, Barcelona, Melusina, 9-302.

SenZ, Silvia y Montserrat Alberte, eds. (2011): El dardo en la Academia. Esencia y vigencia de las academias de la lengua española, 2 vols., Barcelona, Melusina. 
Senz, Silvia, Minguell, J. y M. Alberte (2011): «Las academias de la lengua española, organismos de planificación lingüística», en Senz, Silvia y Montserrat Alberte, eds., El dardo en la Academia. Esencia y vigencia de las academias de la lengua española, vol. 1, Barcelona, Melusina, 372-550.

SolÀ, Joan (1994): Sintaxi normativa: estat de la qüestió, Barcelona, Empúries.

SolÀ, Joan (2000): «Reflexió breu sobre el concepte de "normativa"», en Macià, Jaume y Joan Solà, eds., La terminologia lingüistica en l'ensenyament secundari. Propostes didàctiques, Barcelona, Graó, 39-46.

SolÀ, Joan (2004): «Descripció i prescripció en la Gramàtica del català contemporani (2002)», en Álvarez, Rosario y Henrique Monteagudo, eds., Norma lingüística e variación. Unha perspectiva desde o idioma galego, Santiago de Compostela, Consello da Cultura Galega/Instituto da Lingua Galega, 31-42.

SolÀ, Joan et alii, dir. (2002): Gramàtica del català contemporani, 3 vols, Barcelona, Empúries.

VENY, Joan (1991): Els parlars catalans: síntesi de dialectologia, Palma, Moll. 
